\title{
Stereochemical analysis of menthol and menthylamine isomers using calculated and experimental optical rotation data
}

\author{
F. Reinscheid, U.M. Reinscheid* \\ NMR-based Structural Biology, Max-Planck-Institute of Biophysical Chemistry, Am Fassberg 11, 37077 Göttingen Germany
}

\section{A R T I C L E I N F O}

\section{Article history:}

Received 10 July 2015

Received in revised form

7 September 2015

Accepted 8 September 2015

Available online 11 September 2015

\section{Keywords:}

Menthol isomers

Menthylamine isomers

Chiral analysis

Optical rotation

Conformation

\begin{abstract}
A B S T R A C T
The complete series of menthol isomers and their corresponding amino derivatives (base and protonated/HCl forms), were investigated using experimental and theoretical data. Our study focused on the conformational and configurational analysis, and revealed that experimental data should be used in combination with calculated data. Furthermore, even in the case of the highly studied member, menthol, discrepancies were found among previously published literature values. We show that the correct determination of the population mix is a must for the correct prediction of the absolute configuration (AC) of neoisomenthol. The neoiso forms are of special interest since a number of structural inconsistences can be found in the literature. We present a stringent proof of the AC of neoisomenthol based on literature information. To the best of our knowledge, the AC of neoisomenthylamine is for the first time shown using experimental and calculated optical rotation data. A correction of a series of publications containing an important error in the assignment of (+)-menthylamine (correct: $(+)$-neomenthylamine) is presented. With 26 data pairs (experimental versus calculated) of optical rotation values a regression is performed. The AC of all 12 compounds, even the most difficult neoiso forms, could be predicted correctly using experimental low-temperature NMR data. Furthermore, if only experimental data with an optical rotation outside the range of $-10<[\alpha]>+10$ are used, all 12 compounds would have been correctly assigned without lowtemperature NMR data as restraints.
\end{abstract}

(C) 2015 Elsevier B.V. All rights reserved.

\section{Introduction}

Menthol represents the most highly studied monoterpene. The development of structure determinations in the field of terpenes was described by Hanson [1]. Menthol and its derivatives are of high commercial interest due to their unique properties such as cooling and flavouring agents [2]. In addition, amino derivatives of the menthol series-the diastereomeric menthylamines (bases and $\mathrm{HCl}$ ), have become important as chiral auxiliaries for asymmetric syntheses [3].

Menthol (Fig. 1a) is the major constituent of the essential oil of the mint family (peppermint: Mentha $x$ piperita and spearmint: Mentha spicata). Gladstone [4] presented optical rotation values for crude oils. Without separation, the hydrocarbon from the oil of Mentha viridis was termed "menthol". Annually, several thousand tons of $(-)$-menthol are consumed. Its biosynthesis starts with

\footnotetext{
* Corresponding author.

E-mail address: urei@nmr.mpibpc.mpg.de (U.M. Reinscheid).
}

geranyldiphosphate, which is converted by the limonene synthase to (-)-limonene. (-)-Limonene itself is also a very important monoterpene used for many pharmaceutical, cosmetic and health care products. Via (+)-pulegone, two carbonyl terpenes ((-)-menthone and (+)-isomenthone) are enzymatically produced. With (-)-menthone as a starting point, menthol reductase forms $(-)$-menthol, and a neomenthol reductase $(+)$-neomenthol. Likewise, with (+)-isomenthone as the substrate, neomenthol reductase produces $(+)$-isomenthol, and the menthol reductase (+)-neoisomenthol [2]. (-)-Menthol is able to activate the TRPM (transient receptor potential cation channel subfamily $\mathrm{M}$ member 8 ) receptor, which can also be activated by temperatures between 8 and $28^{\circ} \mathrm{C}$. This receptor is also known as cold and menthol receptor 1 (CMR1) [5]. Derivatives of the menthol isomers are patented as cooling agents [6]. The effective concentration (EC50) is $4.1 \mu \mathrm{M}$ for (-)-menthol and almost 4 times higher for (+)-menthol $(\mathrm{EC} 50=14.4 \mu \mathrm{M})$ [5].

Overall, published literature concerning the stereochemical analysis of the menthol isomers mostly focuses on menthol. The 
first report available based on the x-ray analysis of the menthol isomers dates back to 1999 [7]. The authors presented data for (-)-menthol and emphasized the difficulties in obtaining suitable crystals. We believe this hindered the X-ray analysis of the other three isomers. Bombicz et al. [7] could not derive the absolute configuration due to very weak anomalous scattering. Menthol is also used as a test molecule for structure elucidation by NMR (nuclear magnetic resonance) [8]. As a cyclohexane derivative, its stereochemical analysis has been the focus of research since

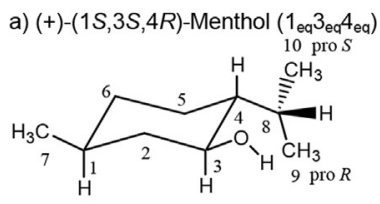

(+)-Menthol: eq/eq/eq; $\mathrm{g}^{+} /$trans
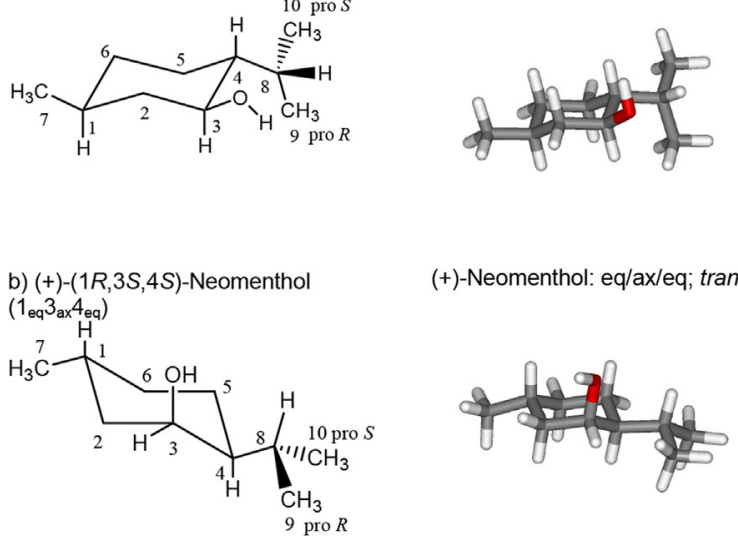

(+)-Neomenthol: eq/ax/eq; trans/ g-

c) $(-)-(1 S, 3 R, 4 S)-$ Isomenthol
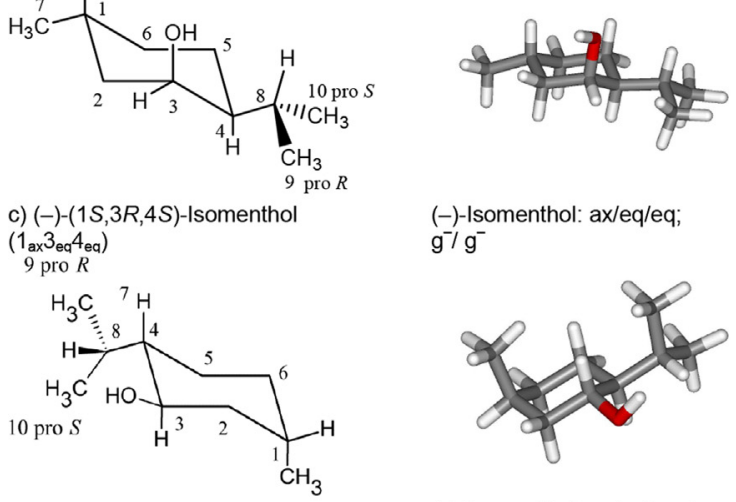

(-)-Isomenthol: ax/eq/eq; $\mathrm{g}^{-} / \mathrm{g}^{-}$

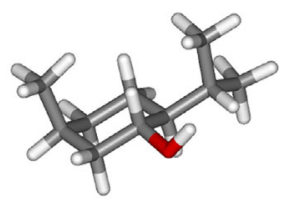

(-)-Isomenthol: eq/ax/ax; trans/ trans

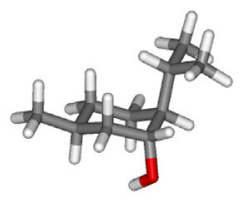

(-)-Neoisomenthol: eq/eq/ax trans/g
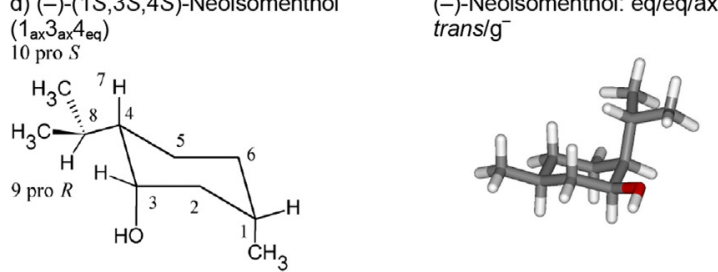

(-)-Neoisomenthol: ax/ax/eq; $\mathrm{g}^{+} / \mathrm{g}^{-}$

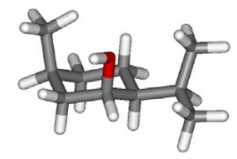

Fig. 1. (a-e). Menthol and the diastereomers neomenthol, isomenthol and neoisomenthol; calculated conformers ${ }^{\mathrm{a}}$ of $(+)-(1 S, 3 S, 4 R)-$ menthol $\quad\left(1_{\mathrm{eq}} 3_{\mathrm{eq}} 4 \mathrm{eq}\right)$ $(+)-(1 R, 3 S, 4 S)-$ Neomenthol $\left(1_{\mathrm{eq}} 3_{\mathrm{ax}} 4_{\mathrm{eq}}\right),(-)-(1 S, 3 R, 4 S)$-Isomenthol $\left(1_{\mathrm{ax}} 3_{\mathrm{eq}} 4_{\mathrm{eq}}\right)$ and $\left(1_{e q} 3_{a x} 4_{a x}\right),(-)-(1 S, 3 S, 4 S)$-Neoisomenthol $\left(1_{1} 3_{2} 4_{a x}\right)$ and $\left(1_{a x} 3_{a x} 4_{e q}\right)$ obtained by DFT (density functional theory) optimization at the mpw1pw91/cc-pvdz level of theory with a continuum solvent model using acetonitrile as solvent [13]. ${ }^{\text {a }}$ : Nomenclature: chair with position of substituents: methyl/OH/isopropyl (eq: equatorial, ax: axial); isopropyl dihedral: $\mathrm{H} 4-\mathrm{C} 4-\mathrm{C} 8-\mathrm{H} 8$; OH dihedral: $\mathrm{H}-\mathrm{O}-\mathrm{C} 3-\mathrm{H} 3$; trans $(t)$, gauche ${ }^{+}\left(\mathrm{g}^{+}\right)$ or gauche ${ }^{-}\left(\mathrm{g}^{-}\right)$. decades [9]. Although computational chemistry has contributed a lot to our present knowledge, it is still mandatory to use experimental information for an accurate conformational analysis of cyclohexanes [10]. This is also nicely illustrated by the report of Basso et al. [11] which revealed that, even for the deceptively simple cis2-halocyclohexanols, it is difficult to correctly predict conformer populations. Therefore, low-temperature NMR data has turned out to be indispensable.

In this report we focus on the stereochemistry in solution of the complete series of menthol stereoisomers (Fig. 1a-e), together with their amino derivatives, both in their base form and protonated. A detailed structural analysis is presented for the parent molecule menthol, the neoiso forms, and menthylamine (base). Our comprehensive analysis aims at providing reliable information concerning the structure and configuration of 12 (four diastereomers of each series) compounds. In conclusion, we present limits of the applied procedure for the AC assignment based on the comparison between calculated and experimental optical rotation values.

\section{Results and discussion}

Nomenclature is highly important in the field of stereochemical analysis. Enantiomers differ in the gauche $e^{+}$gauche ${ }^{-}$descriptors. A dihedral of gauche $e^{-}$in (-)-menthol, is gauche $e^{+}$in (+)-menthol. Many misconceptions have arisen as the definition of the dihedral varies among published reports. In a recent publication, the dihedral was without definition since the cited report did not contain the relevant information [12].

We used the following short hand notation (Fig. 1a-e): chair with the position of substituents in the following order: methyl/ $\mathrm{OH} /$ isopropyl (e.g. $1_{\mathrm{eq}} 3_{\mathrm{eq}} 4_{\mathrm{eq}}$ equals eq/eq/eq) (eq: equatorial, ax: axial); isopropyl dihedral: $\mathrm{H} 8-\mathrm{C} 8-\mathrm{C} 4-\mathrm{H} 4$, OH dihedral: $\mathrm{H}-\mathrm{O}-\mathrm{C}-\mathrm{H}$; trans $(\mathrm{t})$, gauche ${ }^{+}\left(\mathrm{g}^{+}\right)$, gauche ${ }^{-}\left(\mathrm{g}^{-}\right)$. Alongside the schematic drawings, geometry optimized representative conformers of the menthol isomers are shown in Fig. 1. Throughout the text the units [degrees* $\left(\mathrm{dm}^{*} \mathrm{~g} / \mathrm{cm}^{3}\right)^{-1}$ ] for $[\alpha$ ] and $\mathrm{Hz}$ for J-couplings are used. Relative conformer populations refer to $298 \mathrm{~K}$ unless otherwise stated.

\subsection{Structural restraints from $N M R^{3} J_{H H}$ coupling constants and ${ }^{13} \mathrm{C}$ chemical shifts}

An important structural parameter for the menthol series is the ${ }^{3} \mathrm{JOH}\left({ }^{3} \mathrm{~J}_{\mathrm{HOCH}}\right)$ coupling constant, which indicates the rotamer population. Overall, measured values show that averaging around the $\mathrm{CO}$ bond should be performed so that the experimental values represent a mixture of gauche and trans rotamers. The ${ }^{3} \mathrm{JoH}$ coupling constants in DMSO (dimethyl sulfoxide) were determined as $5.6 \mathrm{~Hz}$, $4.9 \mathrm{~Hz}$, overlap, and $3.5 \mathrm{~Hz}$ for menthol, isomenthol, neomenthol, and neoisomenthol, respectively [14]. For a detailed analysis refer to the individual compound sections.

Two other stereochemical aspects are important: the chair type and the isopropyl dihedral. We analysed the experimental and calculated ${ }^{3} \mathrm{~J}_{\mathrm{H} 4 \mathrm{H} 8}$ coupling constants to derive an average value for the isopropyl dihedral.

The ${ }^{3} \mathrm{~J}_{\mathrm{H} 4 \mathrm{H} 8}$ coupling constants were measured in $\mathrm{CDCl}_{3}$ [15]. The ${ }^{3} \mathrm{JH}_{\mathrm{H} 48}$ coupling constants of menthol $(2.5 \mathrm{~Hz})$, neomenthol $(9.1 \mathrm{~Hz})$, and isomenthol $(4.2 \mathrm{~Hz})$ indicate dominant isopropyl rotamers for menthol and neomenthol, and substantial conformational averaging of the isopropyl rotamers of isomenthol. The ${ }^{3} \mathrm{~J}_{\mathrm{H} 4 \mathrm{H} 8}$ coupling constant of neoisomenthol could not be measured due to severe overlap.

Low-temperature ${ }^{13} \mathrm{C}$ chemical shifts in $\mathrm{CD}_{2} \mathrm{Cl}_{2}$ [16] could be applied for the population analysis based on room temperature 
data in $\mathrm{CDCl}_{3}$ [17] since the experimental optical rotation is similar between the two solvents [18]. Clearly, the direct influence of the solvent on the ${ }^{13} \mathrm{C}$ chemical shift is quite small and the solvent dependent conformer populations are the major determinant for the chemical shifts under conditions of fast exchange, which is valid for room temperature for isomenthol and neoisomenthol. Since a very good fit between experimental ${ }^{13} \mathrm{C}$ resonances in chloroform and the calculated resonances with acetonitrile as solvent was observed, we regard acetonitrile as being a good representative even for more apolar solvents. Taking the solvent parameters used into account [19], acetonitrile seems to be a good compromise for simulating experimental solvents such as chloroform, ethanol, and pure solute, in the case of menthol isomers, a secondary alcohol.

\subsection{Structural analysis of the menthol-type isomers}

With all 12 menthol-type isomers (menthols, menthylamines as base and protonated) a conformational search with Discovery Studio (Accelrys [20], Charmm force field, BEST search algorithm, in vacuo) and subsequent DFT calculations (Gaussian09 [21], level of theory: mpw1pw91/cc-pvdz, IEFPCM (integral equation formalism polarizable continuum model): acetonitrile as solvent) with the conformers lowest in energy (cut-off: $2 \mathrm{kcal} / \mathrm{mol}$ ) were conducted. The DFT calculations comprised geometry optimization, frequency calculations to obtain free energies to calculate the Boltzmannweighted populations, calculations of NMR parameters such as ${ }^{13} \mathrm{C}$ chemical shifts and J-coupling constants, and optical rotation calculations.

During the analysis of the menthol conformers, it became clear that the $\mathrm{OH}$ rotamers have to be calculated. Therefore, for menthol, neomenthol and isomenthol, all $\mathrm{OH}$ rotamers of the dominant conformers obtained by the conformational search using a forcefield and subsequent DFT optimization were calculated. For neoisomenthol and neoisomenthylamine, all 18 combinations (2 chairs, $3 \mathrm{OH}$ rotamers, 3 isopropyl rotamers) were calculated.

The $\mathrm{OH}$ rotamers are a very important factor in the configurational analysis using chiroptical methods. In the near IR region, the experimental ECD (electronic circular dichroism) spectra of endoborneol enantiomers more successfully matched with calculations if equal populations of the three $\mathrm{OH}$ rotamers are assumed, in contrast to the energy calculation which indicates one predominant (51.5\%) conformer [22]. In a recent study, Qiu et al. [23] investigated the tadalafil isomers by chiroptical and NMR methods. The authors showed that the population mixes differ if different levels of theory are used for energy calculations. Rottmannová et al. [24] investigated 1,2,4-trihydroxy-para-menthane using calculated and experimental NMR data. In the case of this compound, an intramolecular $\mathrm{H}$-bond is possible, which will restrict at least two $\mathrm{OH}$

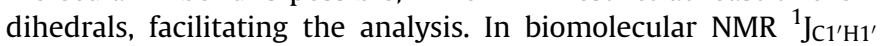
coupling constants have been used for structural modelling of RNA (ribonucleic acid), as these coupling constants depend on the $\mathrm{OH}$ dihedral, and therefore can be used to determine this important dihedral $[25,26]$.

In the present report we used ORD data obtained in solution, meaning that solvent effects had to be modelled in both the configurational and conformational analyses. Several factors had to be taken into account at different stages of the analysis: geometry optimization (structural model), energies (population mix), NMR parameters such as chemical shift and J coupling constants (structural model, population mix), chiroptical data such as ORD (optical rotation dispersion), ECD, and VCD (vibrational circular dichroism).

In the field of configurational analysis, the modelling of solvent effects on chiroptical properties is of great importance (see the review of Mennucci et al.) [13]. The continuum models often account for large parts of the solvent effects. They have been applied often successfully for the prediction of NMR chemical shifts [27]. Polavarapu [28] presented important points for consideration for incorporation of solvent effects into the configurational analysis. A detailed study of limonene has shown that the mpw1pw91/ccpvdz level of theory delivers reliable results for the calculation of ${ }^{13} \mathrm{C}$ chemical shifts [29]. In addition, this level of theory was successful in the geometry optimization of a low-populated conformer of strychnine, base and $\mathrm{HCl}[30,31]$.

However, specific, local effects such as H-bonding are neglected. Generally, two procedures are applied to take these effects into account: 1 . the formation of supermolecules consisting of solute and a sufficient large layer of solvent molecules; 2. calculation and averaging of MD (molecular dynamics)/Monte Carlo snapshots. However, both procedures are difficult to use for chiroptical property prediction. One very important point to consider, for both approaches, is the system definition. Depending on the choice, the predicted value may differ rendering the experimental comparison unreliable. Furthermore, the solvent shell can become chiral and thus experiments are needed to decide if this induced chirality is a computational artefact, or real [13]. If an aggregation is proven, the supermolecule approach should be the best choice.

\subsection{1. (+)-(1S,3S,4R)-menthol}

Using a conformational search and subsequent DFT optimization we found a dominant chair with all three substituents in the equatorial position for menthol (Fig. 1a, Table 1), in agreement with a crystal structure for (-)-menthol [7]. Likewise, at low temperature $\left(-193{ }^{\circ} \mathrm{C}\right)$ Pekh et al. observed only one chair conformer in dichloromethane [16].With the assumption that all three $\mathrm{OH}$ rotamers of the dominant conformer are populated, we calculated the trans, $\mathrm{g}^{+}$and $\mathrm{g}^{-}$rotamers of the $\mathrm{OH}$ eq chair of (+)-menthol with the isopropyl group in the $\mathrm{g}^{+}$position (Table 1 ). In agreement of our analysis, Lomas [32] investigated (-)-menthol and found the $\mathrm{g}^{-}$rotamer of the isopropyl group as dominant conformer, with the crystal structure revealing the isopropyl group in the gauche position [7]. However, pure computational results differ even between similar levels of theory (Table 2). Therefore, we propose to use experimental data for supporting or revising the calculated data.

With the conformers of Table 1 , we calculated a ${ }^{3} \mathrm{JoH}$ coupling constant of $4.9 \mathrm{~Hz}$, which fits the experimental value of $5.6 \mathrm{~Hz}$ in DMSO [14]. Likewise, the calculated ${ }^{3}$ Jisopropyl coupling constant of $1.7 \mathrm{~Hz}$ fits the experimental value of $2.5 \mathrm{~Hz}$ in $\mathrm{CDCl}_{3}$. The calculated ${ }^{13} \mathrm{C}$ population-weighted shieldings gave a good fit with the experimental chemical shifts $\left(y=193.8 \mathrm{ppm}-0.97^{*}\right.$ chemical shift [ppm] of experiment; standard error of intercept and slope, 0.83 ppm and 0.022 ppm, respectively, $\mathrm{R}^{2}=0.9959, \mathrm{n}=10$ ) (see

\section{Table 1}

Calculated parameters of the $\mathrm{OH}$ rotamers of the OHeq chair with a $\mathrm{g}^{+}$isopropyl dihedral of $(+)-(1 S, 3 S, 4 R)$-menthol (eq/eq/eq) (mpw1pw91/cc-pvdz, IEFPCM: acetonitrile).

\begin{tabular}{lccc}
\hline Isopropyl/OH dihedral & $\mathrm{g}^{+} /$trans & $\mathrm{g}^{+} / \mathrm{g}^{+}$ & $\mathrm{g}^{+} / \mathrm{g}^{-}$ \\
\hline $\mathrm{H} 8-\mathrm{C} 8-\mathrm{C} 4-\mathrm{H} 4$ & +69.8 & +64.5 & +67.2 \\
$\mathrm{H}-\mathrm{O}-\mathrm{C} 3-\mathrm{H} 3$ & -178.8 & +50.2 & -80.5 \\
{$[\alpha]_{589}$} & +43.3 & +3.8 & +80.5 \\
{$[\alpha]_{578}$} & +44.9 & +3.85 & +83.9 \\
{$[\alpha]_{546}$} & +50.7 & +4.08 & +94.9 \\
{$[\alpha]_{436}$} & +82.9 & +4.14 & +157.3 \\
{$[\alpha]_{405}$} & +97.8 & +3.43 & +186.9 \\
{$[\alpha]_{366}$} & +124.2 & +0.98 & +240.3 \\
rel. free energy (kcal/mole) & 0 & 0.30 & 0.12 \\
population $(\%)$ & 41.2 & 24.9 & 33.9 \\
${ }_{3}^{3} J_{\text {oH }}[\mathrm{Hz}]$ & 9.85 & 2.13 & 0.83 \\
${ }_{3}^{3} J_{\text {isopropyl }}[\mathrm{Hz}]$ & 1.55 & 1.85 & 1.75 \\
\hline
\end{tabular}


Table 2

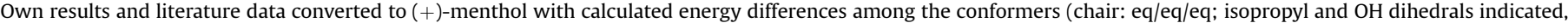
energies in $\mathrm{kcal} / \mathrm{mole}$ ).

\begin{tabular}{|c|c|c|c|c|c|c|c|}
\hline Isopropyl/OH dihedral & $\mathrm{g}^{+} /$trans & $\mathrm{g}^{+} / \mathrm{g}^{+}$ & $\mathrm{g}^{+} / \mathrm{g}^{-}$ & $\mathrm{g}^{-} /$trans & $\mathrm{g}^{-} / \mathrm{g}^{-}$ & trans/trans & trans $/ \mathrm{g}^{-}$ \\
\hline This study mpw1pw91/cc-pvdz (IEFPCM: acetonitrile) & 0 & 0.3 & 0.12 & - & - & - & - \\
\hline $\mathrm{RHF} / 6-31 \mathrm{G}^{*}$ In vacuo $[35]$ & - & - & 0 & - & 0.76 & - & 2.4 \\
\hline B3LYP/6-31G* in vacuo [35] & - & - & 0 & - & 0.5 & - & - \\
\hline B3LYP/cc-pvdz in vacuo [34] & 0 & 0.84 & 0.33 & 0.53 & 0.74 & 1.72 & 2.11 \\
\hline B3LYP/6-31 + G* in vacuo [34] & 0.22 & 0.57 & 0 & 1.20 & 1.03 & 2.61 & 2.30 \\
\hline B3LYP/cc-pvdz/PCM CCl 4 [34] & 0.10 & 0.36 & 0 & 1.20 & 1.08 & 2.58 & 2.39 \\
\hline B3LYP/6-31G** In vacuo [36] & 0 & 0.71 & 0.25 & 0.59 & 0.93 & 1.86 & 2.29 \\
\hline B3LYP/aug-cc-pvtz in vacuo [37] & 0.24 & 0.45 & 0 & 1.27 & 1.08 & - & - \\
\hline B3LYP/6-311++ G(d,p) in vacuo [37] & 0.22 & 0.48 & 0 & 1.20 & 1.00 & - & - \\
\hline MP2/6-311++G (d,p) in vacuo [37] & 0.33 & 0.50 & 0 & 1.20 & 0.79 & - & - \\
\hline B3LYP/6-311+G* in vacuo [33] & 0.31 & - & 0 & 1.22 & 0.96 & - & - \\
\hline $\mathrm{MP} 2 / 6-311+\mathrm{G}^{*}$ in vacuo $[33]$ & 0.45 & - & 0 & - & - & - & - \\
\hline
\end{tabular}

Table S1 in the supporting information). A CMAE (corrected mean absolute error, defined as sum of the absolute differences between calculated (using the linear regression) and experimental values, divided by the number of data pairs) of $0.62 \mathrm{ppm}$ resulted, if the alcoholic C3 was excluded. Since we calculated an isolated molecule, H-bonding in chloroform is neglected as it might heavily influence the chemical shift of $\mathrm{C} 3$. For neoisomenthol, the regression parameters were later used for transforming calculated shieldings into chemical shifts.

In agreement with our results in the solution phase, Albrecht et al. [33] found by IR (infra-red) spectroscopy in the gas phase, a chair conformation in which the $\mathrm{OH}$ group is equatorial in menthol. Although the $\mathrm{OH}$ group positions differ with respect to the cyclohexane chair (equatorial to axial), the $\mathrm{OH}$ wavenumber of the stretching mode is similar: $3654 \mathrm{~cm}^{-1}$ and $3655 \mathrm{~cm}^{-1}$ for menthol and neomenthol, respectively. The dominant $\mathrm{OH}$ dihedral was determined as $\mathrm{g}^{+}$for $(-)$-menthol and the isopropyl dihedral as $\mathrm{g}^{-}$ for (-)-menthol. This is partly in agreement with our results for (+)-menthol: a gauche $e^{+}$isopropyl dihedral but a trans $\mathrm{OH}$ dihedral in solution. Importantly, Albrecht et al. [33] described several levels of theories which did not give reliable relative energies, and thus a population analysis could not be performed. Based on experimental data it was concluded that the B97D functional provided qualitatively incorrect results. From the experimental ${ }^{3} \mathrm{JOH}$ coupling constant, however, it is clear that a mix of $\mathrm{OH}$ rotamers exist in solution, with balanced trans and gauche populations. Therefore we believe that our calculated populations are close to the real values. Furthermore, similar to our findings, Senda and Imaizumi [38] predicted $100 \%$ of the equatorial $\mathrm{OH}$ group for menthol based on free energy estimates for the different substituents being equatorial or axial. Likewise, Jensen [39] assumed $100 \%$ of the equatorial $\mathrm{OH}$ group for menthol based on the bandwidth measurements of the $\mathrm{H} 3$ resonance, presumably in $\mathrm{CCl}_{4}$ as solvent.

Based on the free energy derived populations of Table 1 we predicted a $[\alpha]_{589}$ value of +46.1 which fits very well to the experimental value of +48.13 in toluene $\left(c=10.05,+20.0^{\circ} \mathrm{C}\right.$, Paine III) [40]. The three rotamers with a $\mathrm{g}^{+}$isopropyl group (Table 2) were used for the calculation of the ORD curve (Table 3 ). The calculated and experimental ORD data from a Jasco application note [40a] show that in the wavelength range from $589 \mathrm{~nm}$ to $365 \mathrm{~nm}$, the ORD curves for menthol are monosignate (Table 3 ). This allows a more reliable prediction of the $\mathrm{AC}$ when compared to a bisignate curve [41] since the zero crossing prediction is not required. The crossing is related to a correct prediction of amplitudes and excitation wavelengths. The latter are quite often associated with a large error. Since it is not clear which electronic excitation, to what extent is affected, there is no systematic way to correct it. In contrast, this can easily be done with ECD spectra, since the predicted UV (ultra-violet) spectra can be used as a guide to adjust the $\mathrm{X}$-axis of the calculated ECD spectra to the experimental one. This procedure is not possible for the ORD curve.

The electronic excitations of the menthol and menthylamine isomers lie in the UV region that is not accessible with typical ECD instruments and solvents. An interesting investigation by Grigor'ev et al. [42] presented data about an induced CD of menthol complexes with ketones such as acetone as solvents. This would allow the assignment of the absolute configuration even for the difficult case of neoisomenthol (vide infra). However, this publication lacks some experimental information (e.g. wavelength), and thus a reproduction of the results is impossible to obtain.

In the following section, we focus on the difficult to analyse neoiso forms, and menthylamine for which an important correction has to be made in the literature. A detailed description of all other compounds can be found in the supporting information.

\subsection{2. (-)-(1S,3S,4S)-neoisomenthol}

It is important to assign the sign of the $[\alpha]_{589}$ value of neoisomenthol to a specific solvent since a solvent-dependent sign change occurs. Our reference solvent is ethanol.

A full conformational search encompassing all possible conformers was performed, motivated by three reasons: (i) Neoisomenthol shows the smallest optical rotation value among the menthol isomers. Only a highly accurate conformational analysis has the ability to reproduce this value; (ii) Hückel et al. [43] mentioned a higher tendency for aggregation of neomenthol and neoisomenthol compared to menthol and isomenthol. The authors concluded that neoisomenthol differed markedly from the other three isomers with respect to conformation and reactivity, and hypothesized that a high flexibility could be responsible for the characteristic behaviour of neoisomenthol, with the possible existence of a non-chair form, e.g. twisted boat; (iii) the $[\alpha]$ of neoisomenthol exhibits a strong solvent dependence. Interestingly, also the $O$-methyl derivative shows strong solvent dependent optical rotations [44].

Table 3

Calculated (acetonitrile) and experimental ORD values of (-)-(1S,3S,4R)-menthol taken from Ref. [40] for (+)-menthol at $578 \mathrm{~nm}$, and a JASCO application note (ethanol, $20^{\circ} \mathrm{C}, 1 \%$ solution) [40a].

\begin{tabular}{lcc}
\hline Wavelength $[\mathrm{nm}]$ & {$[\alpha]_{\exp }$} & {$[\alpha]_{\text {calc }}$} \\
\hline 589 & -50 & -46.1 \\
578 & $+50.39^{\mathrm{a}}$ & -47.9 \\
546 & -60 & -54.1 \\
436 & -95 & -88.5 \\
405 & -115 & -104.5 \\
365 & -145 & -132.9 \\
\hline
\end{tabular}

a $20.0^{\circ} \mathrm{C}$, toluene, $\mathrm{c}=10.05$, ( + )-menthol enantiomer [40]. 
Consequently, we built, and geometry optimized 18 chair conformers of (-)-neoisomenthol with ethanol as a solvent as it is the reference solvent for the optical rotation of neoisomenthol (2 chairs, 3 rotamers of the $\mathrm{OH}$ group, 3 rotamers of the isopropyl group). All data of Table 4A (OHeq chair) and B (OHax chair) were obtained with ethanol as solvent, with the four dominant conformers selected for further analysis indicated in bold, and the optical rotations calculated on three levels of theory.

The OHax:OHeq ratio was found to be $87: 13$. With the populations and $[\alpha]_{589}$ values of Table $4 A$ and $B$, the incorrect sign is predicted: $+15.4,+24.3$, and +20.8 for the three levels of theory for $(-)-(1 S, 3 S, 4 S)$-neoisomenthol (experimental $[\alpha]_{589}$ value in ethanol: +1.98 for $(+)-1 R, 3 R, 4 R)$-neoisomenthol $\left(\mathrm{c}=4.028,20^{\circ} \mathrm{C}\right)$ [18].

Calculated enthalphies instead of the free energies in Table $4 \mathrm{~A}$ and $\mathrm{B}$ were used. This procedure is justified due to the large error in the calculated entropic term, but did not change the result: a slightly increased OHeq chair population of $19.8 \%$, but still the incorrect sign of the specific optical rotation: +9.3 for the $(S)$ enantiomer of neoisomenthol (IEFPCM: ethanol) (see supporting information, Tables S9C and D).

Interestingly, if a factor is applied to the data of Table $4 \mathrm{~A}$ and $\mathrm{B}$ that calibrates the two chair forms to a ratio of 60:40 (OHax:OHeq) using ethanol as solvent, the $[\alpha]_{589}$ values of the three levels are found to be: $-2.2 /+2.9 /+0.2$. Although this ratio gives at least with one basis set the correct sign of the optical rotation, it is not clear if the individual $\mathrm{OH}$ and isopropyl rotamers can be scaled in this way since we do not have an experimental value for ${ }^{3} \mathrm{~J}_{\text {isopropyl, }}$ and the ${ }^{3} \mathrm{JoH}$ indicates averaging $(3.5 \mathrm{~Hz})$. Furthermore, for a population analysis with all 18 conformers too few parameters are available: at best $10{ }^{13} \mathrm{C}$ resonances, and $2^{3} \mathrm{~J}$ coupling constants. The inclusion of other parameters such as proton chemical shifts is currently not possible due to heavy overlap and strong coupling constant artefacts. Therefore, a full proton assignment has yet to be performed. In addition, a fraction of resonances showed only small differences among the conformers.

One solution is to analyse a smaller number of conformers which are selected to represent a large fraction of molecules based on the calculated energies. As a first step we used the experimentally determined chair ratio by Pekh et al. [16]. At $193 \mathrm{~K}$ in $\mathrm{CD}_{2} \mathrm{Cl}_{2}$ two sets of signals were obtained which were

\section{Table 4A}

Calculated dihedrals and populations based on free energy differences weighted by the Boltzmann equation (mpw1pw91/cc-pvdz, IEFPCM: ethanol), $[\alpha]_{589}$ at three different levels of theory (level 1: mp1pw91/cc-pvdz, IEFPCM: ethanol; level 2: mp1pw91/aug-cc-pvdz, IEFPCM: ethanol; level 3: mp1pw91/cc-pvtz, IEFPCM: ethanol) of the OHeq chair of $(-)-(1 S, 3 S, 4 S)$-neoisomenthol.

\begin{tabular}{lllllll}
\hline Isopropyl dihedral & $\mathrm{g}^{+}$ & $\mathrm{g}^{-}$ & $\mathrm{t}$ & $\mathrm{g}^{+}$ & $\mathrm{g}^{-}$ & $\mathrm{t}$ \\
OH dihedral & $\mathrm{g}^{+}$ & $\mathrm{g}^{+}$ & $\mathrm{g}^{+}$ & $\mathrm{g}^{-}$ & $\mathrm{g}^{-}$ & $\mathrm{g}^{-}$ \\
Isopropyl dihedral & 82.0 & -78.2 & -166.4 & 84.3 & -76.5 & 161.1 \\
OH dihedral & 56.3 & 59.1 & 61.7 & -63.6 & -63.3 & -63.7 \\
Dipole moment [D] & 1.87 & 1.78 & 1.77 & 1.95 & 1.82 & 2.11 \\
Population [\%] & 0.05 & 0.44 & 6.44 & 0.05 & 0.34 & 4.10 \\
{$[\alpha]_{589}$ level 1 } & -38.2 & -93.2 & -63.1 & +45.4 & -10.4 & +4.1 \\
{$[\alpha]_{589}$ level 2 } & -28.4 & -90.1 & -64.6 & +47.8 & -12.8 & -11.9 \\
{$[\alpha]_{589}$ level 3 } & -35.4 & -88.6 & -68.1 & +42.1 & -7.9 & -6.4 \\
\hline Isopropyl dihedral & & $\mathrm{g}^{+}$ & & $\mathrm{g}^{-}$ & & $\mathrm{t}$ \\
OH dihedral & & $\mathrm{t}$ & & $\mathrm{t}$ & & $\mathrm{t}$ \\
Isopropyl dihedral & & 81.6 & & -73.2 & & 162.5 \\
OH dihedral & & -167.4 & & -168.0 & & -173.9 \\
Dipole moment & & 1.98 & & 1.76 & & 2.10 \\
{$[\mathrm{D}]$} & & & & & & \\
Population [\%] & & 0.02 & & 0.32 & & 1.02 \\
{$[\alpha]_{589}$ level 1 } & & -41.9 & & -64.8 & & -69.3 \\
{$[\alpha]_{589}$ level 2 } & & -42.9 & & -64.5 & & -34.9 \\
{$[\alpha]_{589}$ level 3 } & & -43.6 & & -59.5 & & -47.9 \\
\hline
\end{tabular}

\section{Table 4B}

Calculated dihedrals and populations based on free energy differences weighted by the Boltzmann equation (mpw1pw91/cc-pvdz, IEFPCM: ethanol), $[\alpha]_{589}$ at three different levels of theory (level 1: mp1pw91/cc-pvdz, IEFPCM: ethanol; level 2: mp1pw91/aug-cc-pvdz, IEFPCM: ethanol; level 3: mp1pw91/cc-pvtz, IEFPCM: ethanol) of the OHax chair of $(-)-(1 S, 3 S, 4 S)$-neoisomenthol

\begin{tabular}{lllllll}
\hline Isopropyl dihedral & $\mathrm{g}^{+}$ & $\mathrm{g}^{-}$ & $\mathrm{t}$ & $\mathrm{g}^{+}$ & $\mathrm{g}^{-}$ & $\mathrm{t}$ \\
OH dihedral & $\mathrm{g}^{+}$ & $\mathrm{g}^{+}$ & $\mathrm{g}^{+}$ & $\mathrm{g}^{-}$ & $\mathrm{g}^{-}$ & $\mathrm{g}^{-}$ \\
Isopropyl dihedral & 64.4 & -81.0 & 175.0 & 54.0 & -75.7 & 172.9 \\
OH dihedral & 63.9 & 45.7 & 59.2 & -66.2 & -66.5 & -65.8 \\
Dipole moment [D] & 2.18 & 1.88 & 1.97 & 1.88 & 1.96 & 1.73 \\
Population [\%] & 1.13 & 1.38 & 20.10 & 2.70 & 4.57 & 39.46 \\
{$[\alpha]_{589}$ level 1 } & +49.1 & -56.4 & -20.5 & +78.2 & +11.9 & +32.2 \\
{$[\alpha]_{589}$ level 2 } & +32.9 & -19.9 & -15.7 & +96.8 & +26.8 & +45.7 \\
{$[\alpha]_{589}$ level 3 } & +41.7 & -37.9 & -15.3 & +92.7 & +23.9 & +40.4 \\
\hline Isopropyl dihedral & & $\mathrm{g}^{+}$ & & $\mathrm{g}^{-}$ & & $\mathrm{t}$ \\
OH dihedral & & $\mathrm{t}$ & & $\mathrm{t}$ & & $\mathrm{t}$ \\
Isopropyl dihedral & & 56.1 & & -75.2 & & 174.1 \\
OH dihedral & & 169.8 & & -178.4 & & 169.6 \\
Dipole moment [D] & & 2.12 & & 2.13 & & 2.02 \\
Population [\%] & & 1.04 & & 0.97 & & 15.87 \\
{$[\alpha]_{589}$ level 1 } & & +88.7 & & +27.7 & & +53.2 \\
{$[\alpha]_{589}$ level 2 } & & +102.5 & & +34.3 & & +61.5 \\
{$[\alpha]_{589}$ level 3 } & & +94.6 & & +30.8 & & +55.6 \\
\hline
\end{tabular}

assumed to belong to the two chair forms. Using the ${ }^{13} \mathrm{C}$ resonances at low temperatures and fitting to the values obtained at room temperature in $\mathrm{CDCl}_{3}$ [17] resulted in a 67:33 (OHax:OHeq) ratio with the lowest CMAE [16]. This is justified since the optical rotation in chloroform is very similar to the value in ethanol, indicating that the chair ratio in these two solvents is similar. The room temperature chemical shifts in $\mathrm{CCl}_{4}$ [16] differ less than $0.5 \mathrm{ppm}$ to the room temperature data in $\mathrm{CDCl}_{3}$ [17]. This means that solvent induced changes in the conformer populations are relatively small, or masked by a concomitantly changed chemical shift due to direct interactions, and/or magnetic susceptibility differences which are not perfectly removed by using TMS as reference.

Next we selected the five mostly populated conformers $(2$ OHeq, 3 OHax) based on calculated energies, calculated the ${ }^{13} \mathrm{C}$ shieldings and used ${ }^{13} \mathrm{C}$ data obtained by low-temperature measurements representing the individual two chairs [16] for multiple regression. Using the calculated values of the three dominant conformers $\mathrm{tg}^{+}, \mathrm{tg}^{-}$and tt of the OHax chair, a population mix of 34:3:63 was obtained. Since the ${ }^{13} \mathrm{C}$ resonances of the latter two differ only slightly (max. difference: $1.62 \mathrm{ppm}$, only two resonance differences bigger than $1.0 \mathrm{ppm}$ ), we selected $\mathrm{tg}^{-}$ as representative conformer. The predicted energy for the $\mathrm{tg}^{-}$ conformer was lower than that for conformer tt. We repeated the regression using only two conformers of the OHax chair: $\operatorname{tg}^{+}$and $\mathrm{tg}^{-}$. With these two conformers we obtained a good fit $\left(\mathrm{R}^{2}=0.993, \mathrm{n}=10\right)$ and a low corrected mean absolute error (CMAE) of $0.41 \mathrm{ppm}$ with all 10 resonances using the population mix of $46: 54$ for $\operatorname{tg}^{+}: \operatorname{tg}^{-}$.

Likewise, the ${ }^{13} \mathrm{C}$ data for the OHeq chair were analysed with the $\mathrm{tg}^{+}$and $\mathrm{tg}^{-}$conformers. A CMAE of $0.85 \mathrm{ppm}$ was obtained for a population mix of $55 / 45$ for $\operatorname{tg}^{+} / \operatorname{tg}^{-}$with all 10 resonances $\left(R^{2}=0.998\right)$. The combination of the four conformers of the two chair forms with a chair ratio of 67:33 (OHax:OHeq) as restraint, gave a population mix of 30.8:36.2:18.2:14.8 ( $\mathrm{OHax}, \mathrm{tg}^{+} / \mathrm{OHax}, \mathrm{tg}^{-}$) $\mathrm{OHeq}, \mathrm{tg}^{+} / \mathrm{OHeq}, \mathrm{tg}^{-}$) which was regressed versus the experimental values at room temperature in $\mathrm{CDCl}_{3}$ [17] using the menthol regression parameters (intercept: $193.8 \mathrm{ppm}$, slope: $-0.97 \mathrm{ppm}$ ). The CMAE amounts to $0.92 \mathrm{ppm}$ using all ten ${ }^{13} \mathrm{C}$ resonances. Based on this good fit between experimental and calculated values based on chair forms, the existence of reasonably populated twisted boat form can be excluded [45]. 
The predicted ${ }^{3} \mathrm{JOH}$ coupling constant of $0.7 \mathrm{~Hz}$ which is much smaller than the experimental value $\left(3.5 \mathrm{~Hz}\right.$ in $\mathrm{CDCl}_{3}$ ), indicates that the predicted $\mathrm{OH}$ gauche/trans ratio is too low. This discrepancy can be explained due to the fact that we exclusively selected the $\mathrm{tg}^{-}$ conformer for the OHax chair instead of the tt conformer. Using a mix of $6 \% \mathrm{tg}^{-}$and $30 \% \mathrm{tt}$, the predicted coupling constant would exactly match the experiment: $3.5 \mathrm{~Hz}$. Of course, this population mix would change the predicted optical rotation: +0.7 for the $S$ enantiomer instead of -5.5 approaching the experimental value of +2.2 for $(+)-(1 R, 3 R, 4 R)$-neoisomenthol, however, with the wrong sign (Table 5). The experimental ${ }^{3} \mathrm{~J}_{\mathrm{H} 4, \mathrm{H} 8}$ coupling constant for neoisomenthol could not be determined due to overlapping resonances. Thus, a comparison with a calculated value is not possible.

Based on the four conformers, the $[\alpha]_{589}$ values of (-)-(1S,3S,4S)-neoisomenthol are $-5.5,-1.8,-3.4$ for the basis sets cc-pvdz, aug-cc-pvdz and cc-pvtz, respectively (experiment: +1.98 for $(+)-1 R, 3 R, 4 R)$-neoisomenthol, $\mathrm{c}=4.028$, ethanol, $20{ }^{\circ} \mathrm{C}$ [18]; +2.2 for $(+)-1 R, 3 R, 4 R$ )-neoisomenthol, $\mathrm{c}=2.0$, ethanol, $16{ }^{\circ} \mathrm{C}$ ) [46]. Magnitude and sign of the experimental ORD data were correctly predicted (Table 5 ).

The most probable explanation for the solvent dependent optical rotation is a solvent dependent conformational equilibrium for neoisomenthol. Hückel and Gupté [47] hypothesized that the chair with the $\mathrm{OH}$ in an axial position is responsible for the negative value in diethylether this appears to be correct for the $(+)-(1 R, 3 R, 4 R)$-neoisomenthol enantiomer. Starting from negative $[\alpha]_{589}$ values for diethylether and cyclohexane ( -12.36 and -8.69$)$, the specific optical rotation becomes positive in more dipolar and $\mathrm{H}$-bond donating solvents such as ethanol $(+1.98)$. This behaviour indicates a strong solvent dependence and probably the H-bond assisted stabilization of conformers and/or stabilization of conformers by solvent polarity. Our data confirm this assumption since the OHax conformers contribute +20.7 to the total calculated $[\alpha]_{589}$ value of +15.4 for $(-)-(1 S, 3 S, 4 S)$-neoisomenthol with a incorrect sign (mpw1pw91/cc-pvdz, IEFPCM: ethanol) (Table 4A and B). The OHeq conformers contribute -5.3 units with the correct sign. The OHax:OHeq ratio is $87: 13$. This indicates a too low population of the OHeq conformers. All solvents increasing the contribution of the OHeq chair such as ethanol would shift the $[\alpha]_{589}$ value of $(-)-(1 S, 3 S, 4 S)$-neoisomenthol towards a negative sign. In more apolar, especially non-H-bond donating solvents such as $\mathrm{CCl}_{4}$ and cyclohexane, the OHax:OHeq ratio is better modelled with a dominant OHax form. Likewise, Cole and Jefferies [48] concluded based on IR spectroscopy of a diol of neoisomenthol that a ratio of at least 80:20 (OHax:OHeq) is present for neoisomenthol in $\mathrm{CCl}_{4}$. In fact, the $[\alpha]_{589}$ values from Table 6 indicate that in this solvent the population of OHax is higher than in ethanol. For a correct sign prediction in ethanol without selecting individual conformers a OHax:OHeq ratio of 60:40 was necessary (vide supra).

Interestingly, using the acidity and dipolarity parameters of Catalán [19] a relatively good regression was obtained using the

\section{Table 5}

Calculated ORD values based on four conformers of (-)-(1S,3S,4S)-neoisomenthol (mpw1pw91/cc-pvdz, IEFPCM: ethanol) and experimental ORD values of (+)-(1R,3R,4R)-neoisomenthol.

\begin{tabular}{lllll}
\hline & {$[\alpha]_{656}$} & {$[\alpha]_{589}$} & {$[\alpha]_{578}$} & {$[\alpha]_{546}$} \\
\hline$(+)-(1 R, 3 R, 4 R)-$ neoisomenthol $^{\mathrm{a}}$ & - & $+0.406^{\mathrm{d}}$ & $+0.425^{\mathrm{d}}$ & $+0.473^{\mathrm{d}}$ \\
$(+)-(1 R, 3 R, 4 R)-$ neoisomenthol $^{\mathrm{a}}$ & $+1.7^{\mathrm{c}}$ & $+2.2^{\mathrm{c}}$ & - & $+2.3^{\mathrm{c}}$ \\
(-)-(1S,3S,4S)-neoisomenthol $^{\mathrm{b}}$ & -4.6 & -5.5 & -5.6 & -6.2 \\
\hline
\end{tabular}

\footnotetext{
${ }^{\mathrm{a}}$ Experimental.

b Calculated with the four selected conformers from above.

c $\mathrm{c}=2.0$, ethanol, $16^{\circ} \mathrm{C}$; [46].

d Neat, $99.3 \%$ pure by GC, at $20.0{ }^{\circ} \mathrm{C}[40]$.
}

Table 6

$[\alpha]$ values of $(+)-(1 R, 3 R, 4 R)$-neoisomenthol at $20{ }^{\circ} \mathrm{C}$ in different solvents [18], solvent acidity (SA) and dipolarity (SdP) [19].

\begin{tabular}{lcccclll}
\hline Solvent & conc. $^{\mathrm{a}}$ & {$[\alpha]_{656}$} & {$[\alpha]_{589}$} & {$[\alpha]_{546}$} & SA & SdP & {$[\alpha]_{546}{ }^{\mathrm{c}}$} \\
\hline Diethyl-ether & 4.044 & -9.89 & $-12.36^{\mathrm{b}}$ & -14.21 & 0 & 0.385 & - \\
Cyclo-hexane & 4.024 & -7.45 & -8.69 & -9.94 & 0 & 0 & -9.05 \\
Hexane & 4.034 & -7.43 & -8.67 & -9.91 & 0 & 0 & -9.05 \\
Chloro-ben-zene & 4.056 & -5.17 & -6.53 & -7.64 & 0 & 0.537 & -5.84 \\
$\mathrm{CCl}_{4}$ & 4.072 & -5.03 & -6.38 & -7.49 & 0 & 0 & -9.05 \\
Ben-zene & 4.022 & -4.97 & -6.34 & -7.45 & 0 & 0.27 & -7.43 \\
Ben-zene & 8.028 & -4.98 & -6.35 & -7.47 & 0 & 0.27 & -7.44 \\
Dioxane & 4.038 & -4.95 & -6.31 & -7.42 & 0 & 0.312 & -7.18 \\
Benzo-nitrile & 4.054 & -3.21 & -3.94 & -4.56 & 0 & 0.852 & -3.96 \\
Aceto-nitrile & 4.036 & -2.10 & -2.47 & -2.84 & 0.044 & 0.974 & -2.48 \\
Chloro-form & 4.080 & -0.37 & -0.61 & -0.98 & 0.047 & 0.614 & -4.57 \\
Ethanol & 4.028 & +1.49 & $+1.98^{\mathrm{b}}$ & +2.11 & 0.4 & 0.783 & +2.49 \\
Ethanol & 8.008 & +1.56 & $+2.00^{\mathrm{b}}$ & +2.18 & 0.4 & 0.783 & +2.49 \\
Acetic acid & 4.076 & +1.96 & +2.70 & +3.18 & 0.689 & 0.676 & - \\
$t$-butanol & 4.060 & +2.96 & +3.83 & +4.80 & 0.145 & 0.732 & - \\
\hline
\end{tabular}

a $\mathrm{g} / 100 \mathrm{ml}$.

b At higher concentrations: $[\alpha]_{589}:+2.2(c=12.8$, ethanol $),[\alpha]_{589}:-12.2(c=14.3$, diethylether [43].

${ }^{c}$ By linear regression: $y=-9.047+17.16 * S A+5.97 * S d P, R^{2}=0.853, n=10$.

optical rotation values at $546 \mathrm{~nm}$ neglecting tert-butanol and diethylether $\left(\mathrm{y}=-9.047+17.16 * \mathrm{SA}+5.97 * \mathrm{SdP}, \mathrm{R}^{2}=0.853\right.$, $\mathrm{n}=10 ;$ SA: solvent acidity; SdP: solvent dipolarity). With increasing solvent acidity and dipolarity, the OHeq is more stabilized than the OHax form due to the formation of 2 instead of $1 \mathrm{H}$ bond $[49,50]$. As an explanation, the following should be considered: the size of an $\mathrm{OH}$ group increases from apolar/aprotic via polar to protic solvents due to the formation of solvent-solute interactions, rendering the $\mathrm{OH}$ group larger in space. Concomitantly, the population of the equatorial form increases [49]. A study of the diffusion of cyclohexanol in different solvent supports this explanation [51]. Importantly, in the apolar/aprotic solvent decane, the diffusion is slowed down compared to acetonitrile which can be explained by the formation of cyclohexanol aggregates (concentration: $10 \mathrm{mg} / \mathrm{ml}$ ).

A selective chair stabilization, due to very different dipole moments among the conformers, can be ruled out as the calculated dipole moments of the conformers (Table $4 \mathrm{~A}$ and $\mathrm{B}$ ) are similar for both chairs: on average the $\mathrm{OH}$ eq conformers have a population weighted dipole moment of 1.91, whereas the $\mathrm{OH}$ ax conformers of 1.87. Even the dominant populations show evenly distributed dipole moments among the two chairs.

Neglecting tert-butanol in the analysis can be rationalized as a too small SA value was obtained in the reference reaction due to steric hindrance. Therefore, the SA value of tert-butanol appears to be too low for the stabilizing interaction with the OHeq form of neoisomenthol. Diethylether cannot stabilize the OHeq chair by dipolar interactions because of accessibility problems, so the SdP value appears to be too large for the interaction with the OHeq form of neoisomenthol.

A similar chair ratio was determined by Feltkamp and Franklin [52] who investigated the solution conformations of the menthol isomers. Based on NMR coupling constants analysed as sum (bandwidth), they determined a 71:29 (OHax:OHeq) ratio for neoisomenthol. Unfortunately, we could not find information concerning the solvent, and we speculate that chloroform or $\mathrm{CCl}_{4}$ was used. Likewise, Jensen [39] obtained a 62:38 ratio (OHax:OHeq), presumably using $\mathrm{CCl}_{4}$ as solvent. These results match the $62: 38$ (OHax:OHeq) ratio obtained by the analysis of the ${ }^{3} \mathrm{~J}_{2} \mathrm{H} 3$ coupling constant in $\mathrm{CDCl}_{3}[15]$.

However, the Boltzmann-weighted energy differences of all 18 conformers led to a 87:13 (OHax:OHeq) ratio which overestimates 
the axial $\mathrm{OH}$ conformers compared to the experimentally based ratios. This might be due to the fact that intermolecular $\mathrm{H}$ bonding to appropriate solvents was not modelled. The equatorial $\mathrm{OH}$ group should be more stabilized in $\mathrm{H}$-bond donor and/or acceptor solvents compared to the axial $\mathrm{OH}$ group which might be extra stabilized in the calculations by an intramolecular $\mathrm{H}$-bond [50]. In addition, this stabilizing effect may be temperaturedependent as has been shown for 3-substituted cyclohexanols [53]. Interestingly, based on empirical energy estimates an inverted ratio of 30:70 (OHax:OHeq) was calculated by Feltkamp and Franklin [59]. Likewise, the dominant chair of neoisomenthol was predicted to bear the $\mathrm{OH}$ in the equatorial position with an OHax/OHeq ratio of 9:91 based on free energy estimates [38], but this conclusion was reached using an incorrect assignment and has to be discarded.

Geometry optimization and energy calculations of a twist-boat form (favourable isoclinal (IC) position: isopropyl group; $\mathrm{OH}$ and $\mathrm{CH}_{3}$ substituents in favourable pseudo-equatorial positions) in three solvents resulted in much higher free energies than the lowest in energy chair conformer in ethanol (ax/ax/eq; trans $/ \mathrm{g}^{-}$): $6.99,6.94$ and $7.74 \mathrm{kcal} / \mathrm{mol}$ in ethanol, acetonitrile, and diethylether (IEFPCM) with trans $/ \mathrm{g}^{+}$dihedrals (isopropyl/OH). The energy difference is reduced in ethanol to $6.2 \mathrm{kcal} / \mathrm{mol}$ at maximum for the $\mathrm{g}^{+} /$trans conformer (isopropyl/OH). The low temperature NMR data and the calculated data clearly indicate that only negligible populations of twist-boat forms might exist in solution. A convincing example of a twist-boat cyclohexane derivative was presented by Gill et al. [54] using cis-1,4-di-tert-butylcyclohexane in propane.

To conclude, the energy calculations of Feltkamp and Franklin [52] and Senda et al. [38] erroneously indicated that the equatorial $\mathrm{OH}$ chair dominates for neoisomenthol. Based on DFT energies, the axial $\mathrm{OH}$ chair dominates $(87: 13$, OHax:OHeq) but this has to be corrected to $67: 33$ using low-temperature NMR ${ }^{13} \mathrm{C}$ data [16]. The 67:33 ratio is further supported by the analysis of experimental ${ }^{3} \mathrm{JH}_{2} \mathrm{H} 3$ coupling constants in $\mathrm{CDCl}_{3}$ [15] and bandwidth measurements of H3 [39].

\subsection{3. (+)-(1S,3S,4R)-menthylamine base}

For all amino derivatives, experimental J-coupling constants are not available in the literature. The conformational search resulted in a chair with all substituents in the equatorial position, with a highly dominant $\mathrm{g}^{+}$/trans conformer with respect to the isopropyl and $\mathrm{NH}_{2}$ group. The $\mathrm{NH}_{2}$ dihedral is defined by HproR$\mathrm{N}-\mathrm{C} 3-\mathrm{H} 3$. Firl et al. [55] estimated for $(+)$-menthylamine the $\mathrm{g}^{+}$ rotamer of the isopropyl group as the dominant conformer. This estimate was based on empirical rules for the dependence of ${ }^{13} \mathrm{C}$ chemical shifts on the position of substituents. This is in agreement with our populations based on calculated energies (Table 7).

As with the menthol series, we additionally calculated all three $\mathrm{NH}_{2}$ rotamers of this dominant conformer with a $\mathrm{g}^{+}$isopropyl group (Table 7). With the populations based on free energies, we

\section{Table 7}

Calculated parameters of the $\mathrm{NH}_{2}$ rotamers of the $\mathrm{NH}_{2}$ eq chair with a $\mathrm{g}^{+}$isopropyl dihedral of $(+)-(1 S, 3 S, 4 R)$-menthylamine (mpw1pw91/cc-pvdz, IEFPCM: acetonitrile).

\begin{tabular}{lccc}
\hline & eq/eq/eq; $\mathrm{g}^{+}$trans & eq/eq/eq; $\mathrm{g}^{+} / \mathrm{g}^{+}$eq/eq/eq; $\mathrm{g}^{+} / \mathrm{g}^{-}$ \\
\hline H8-C8-C4-H4 & 68.0 & 65.0 & 60.6 \\
HproR-N-C3-H3 & -175.2 & 58.5 & -66.2 \\
{$[\alpha]_{589}$} & +75.5 & -13.6 & +28.3 \\
rel. free energy (kcal/mole) & 0 & 0.66 & 1.31 \\
Population (\%) & 69.4 & 22.9 & 7.7 \\
${ }_{3}^{\text {Jisopropyl }[\mathrm{Hz}]}$ & 1.8 & 1.9 & 2.3 \\
\hline
\end{tabular}

predicted a $[\alpha]_{589}$ value of +57.3 for the $(+)$ enantiomer (Table 8 ) which fits roughly to the experimental value of -35.70 ( $c=1.39$, chloroform, $20^{\circ} \mathrm{C}$ ) for (-)-menthylamine [56]. De Vekki et al. [57] reported a $[\alpha]_{589}$ value of -24.0 at $20^{\circ} \mathrm{C}$ for the neat compound. The calculated and experimental ORD values are shown in Table 8. A population-weighted ${ }^{3} \mathrm{~J}_{\text {isopropyl }}$ coupling constant of $1.8 \mathrm{~Hz}$ is predicted.

Importantly, in a series of recent publications $[58,59]$ the authors claimed to have synthesized (+)-menthylamine. In the first article, the experimental section contains several typing errors which indicate $(-)$ instead of $(+)$ [58]. In addition, the formula which is shown represents (+)-neomenthylamine, yet in fact, the presented experimental data in chloroform (not assigned ${ }^{13} \mathrm{C}$ and $\left.[\alpha]_{589}\right)$ clearly shows that $(+)$-neomenthylamine has been prepared. In comparison with the experimental values of Firl et al. [55] in the same solvent, the MAE (mean absolute error) was found to be $1.9 \mathrm{ppm}$ for menthylamine and $0.07 \mathrm{ppm}$ for neomenthylamine, clearly indicating that neomenthylamine has been synthesized. The data of Firl et al. [55] are similar to Schopohl et al. [56] with differences less than $1 \mathrm{ppm}$. In addition, the experimental $[\alpha]_{589}$ of Zhou et al. [58] for the (+)-enantiomer was found to be $+5.4\left(\mathrm{c}=0.6, \mathrm{CHCl}_{3}\right.$ at $\left.25^{\circ} \mathrm{C}\right)$ and -35.7 for the $(-)$ enantiomer of menthylamine $\left(\mathrm{c}=1.39\right.$, chloroform, $20{ }^{\circ} \mathrm{C}$ ) [56] but +11.6 (c $=1.0$, chloroform, $20^{\circ} \mathrm{C}$ ) for the $(+)$ enantiomer of neomenthylamine [3]. Interestingly, in the crucial synthetic step of the reduction of the oxime, apart from $(+)-(1 R, 3 S, 4 S)$-neomenthylamine, (-)-(1R,3R,4S)-menthylamine was obtained. With an incomplete purification, the presence of the last compound as impurity could explain the reduced specific optical rotation obtained compared to the data of Kulisch et al. [3]. Furthermore, the literature cited to justify the assignment $\left([\alpha]_{589}:+6.5, c=0.54\right.$, $\mathrm{CHCl}_{3}$ at $20{ }^{\circ} \mathrm{C}$ ) is incorrect [60], as the synthetic schemes contain clear mistakes: the depicted formulas of the intermediates represent neomenthylamine instead of menthylamine, and the final products show erroneously two different substituents for the urea and isocyanate derivatives. In summary, the aforementioned series of articles all contain the incorrect name of the chiral ligand for asymmetric synthesis: (+)-neomenthylamine has been prepared instead of $(+)$-menthylamine.

\subsection{4. (-)-(1S,3S,4S)-neoisomenthylamine base}

Notably, the assignment of neoisomenthylamine as base uses chloroform as solvent. To the best of our knowledge, only a synthetic approach was used for assignment of the absolute configuration, starting with enantiomerically pure and known isomenthone [61]. With respect to the date of publication, it is important to re-assign the AC of this compound. We could only find an ad hoc assignment without referring to valid experimental data [62]. In the present report we demonstrate the first spectroscopical assignment of the AC of neoisomenthylamine base, likewise of the protonated form, or experimentally, the hydrochloride (vide infra).

Similar to neoisomenthol, the full series of conformers were geometry optimized. Structural parameters and populations based

\section{Table 8}

Calculated ORD values of (+)-menthylamine (mpw1pw91/cc-pvdz, IEFPCM: acetonitrile) and experimental ORD values of (-)-menthylamine, $\mathrm{c}=1.39, \mathrm{CHCl}_{3}, 20{ }^{\circ} \mathrm{C}$ [56].

\begin{tabular}{lcr}
\hline Wavelength in $\mathrm{nm}$ & {$[\alpha]_{\exp }$} & {$[\alpha]_{\text {calc }}$} \\
\hline 589 & -35.7 & +57.3 \\
578 & -37.1 & +59.6 \\
546 & -41.9 & +67.4 \\
436 & -67.6 & +110.9 \\
365 & -98.9 & +167.6 \\
\hline
\end{tabular}


on calculated free energies and $[\alpha]_{589}$ values are presented in Table $9 \mathrm{~A}$ and $\mathrm{B}$.

To date low temperature ${ }^{13} \mathrm{C}$ experimental NMR data for neoisomenthylamine has not been reported. With the calculated populations based on free energies a specific optical rotation of +7.2 for $(1 S, 3 S, 4 S)$-neoisomenthylamine was obtained with an $\mathrm{NH}_{2}$ ax: $\mathrm{NH}_{2}$ eq ratio of $61: 39$. Based on calculated energies, the amino group stabilizes the $\mathrm{NH}_{2} \mathrm{eq}$ chair more than the $\mathrm{OH}$ group in neoisomenthol. The sign of the $[\alpha]_{589}$ value does not fit the experimental value of +11.0 in chloroform for the $(1 R, 3 R, 4 R)$ enantiomer ( $c=$ between 2 and 4) [63]. This prompted us to reproduce the experimental conditions and repeat the calculations with chloroform as solvent (geometry optimization, population analysis based on free energy differences, optical rotation calculations; see supporting info, Tables S14A and B). A value of +10.2 was calculated for $[\alpha]_{589}$ using the population mix based on calculated free energies and this still has an incorrect sign compared to the experimental data.

As a second approach to obtain a better fit with experimental conditions, we selected the same four conformers as for neoisomenthol, and adjusted the populations based on calculated free energies in order that they represent $100 \%$ of the conformers (12.8:27.9:14.5:44.8; $\mathrm{NH}_{2} \mathrm{eq}, \mathrm{tg}^{+} / \mathrm{NH}_{2} \mathrm{eq}, \mathrm{tg}^{-} / \mathrm{NH}_{2} \mathrm{ax}, \mathrm{tg}^{+} / \mathrm{NH}_{2} \mathrm{ax}, \mathrm{tg}^{-}$) (Table 10). Using these we calculated the ORD data (Table 11) that match quite well to the experiment. In fact, the analysis of the protonated form (experimentally: the $\mathrm{HCl}$ salt) shows that the $\mathrm{NH}_{2}$ eq forms are more highly populated in the experiment than in the calculations. We therefore hypothesize that the same reasoning applies as for neoisomenthol (vide supra).

\subsection{5. (-)-(1S,3S,4S)-neoisomenthylamine protonated}

Calculations with all six staggered conformations were performed (Table 12). Interestingly, the protonation inverts the chair ratio and now favours the equatorial form with respect to the $\mathrm{NH}_{2}$ group based on calculated free energies: $\mathrm{NH}_{2} \mathrm{ax}: \mathrm{NH}_{2} \mathrm{eq}, 38.7: 61.3$. This ratio should be compared to 61:39 $\left(\mathrm{NH}_{2} \mathrm{ax}: \mathrm{NH}_{2} \mathrm{eq}\right)$ of (-)-neoisomenthylamin as base. Using all six conformers, the predicted $[\alpha]_{589}$ value was -9.4 for the $(1 S, 3 S, 4 S)$ enantiomer which fits the experimental value of +20.9 for the $(1 R, 3 R, 4 R)$ enantiomer ( $c=2$, water) [63]. The absolute calculated value changed to -4.8 at $546 \mathrm{~nm}$.

For the protonated neoisomenthylamine, all $\mathrm{NH}_{2} \mathrm{eq}$ conformers contribute with a negative sign, and all $\mathrm{NH}_{2} \mathrm{ax}$ conformers contribute with a positive sign to the optical rotation. The $\mathrm{NH}_{2} \mathrm{ax}$ forms contributes +16.7 and the $\mathrm{NH}_{2}$ eq forms -26.1 to the $[\alpha]_{589}$ value. In this case, a clear decision can be made which chair is dominant.

\section{Table 9A}

Calculated dihedrals and populations based on free energy differences weighted by the Boltzmann equation (mpw1pw91/cc-pvdz, IEFPCM: acetonitrile) and $[\alpha]_{589}$ values (mp1pw91/cc-pvdz, IEFPCM: acetonitrile) of the $\mathrm{NH}_{2} \mathrm{eq}$ chair of $(-)-(1 S, 3 S, 4 S)$-neoisomenthylamine.

\begin{tabular}{lllllll}
\hline Isopropyl dihedral & $\mathrm{g}^{+}$ & $\mathrm{g}^{-}$ & $\mathrm{t}$ & $\mathrm{g}^{+}$ & $\mathrm{g}^{-}$ & $\mathrm{t}$ \\
$\mathrm{NH}_{2}$ dihedral & $\mathrm{g}^{+}$ & $\mathrm{g}^{+}$ & $\mathrm{g}^{+}$ & $\mathrm{g}^{-}$ & $\mathrm{g}^{-}$ & $\mathrm{g}^{-}$ \\
Isopropyl dihedral & 66.0 & -73.2 & -151.3 & 82.6 & -77.7 & -161.3 \\
$\mathrm{NH}_{2}$ dihedral & 81.0 & 69.0 & 67.4 & -59.07 & -58.0 & -56.6 \\
population [\%] & 0.1 & 4.4 & 8.7 & 0.2 & 3.0 & 18.8 \\
{$[\alpha]_{589}$} & -79.1 & -107.4 & -105.9 & +1.9 & -45.4 & -26.1 \\
\hline Isopropyl dihedral & & $\mathrm{g}^{+}$ & & $\mathrm{g}^{-}$ & & $\mathrm{t}$ \\
$\mathrm{NH}_{2}$ dihedral & & $\mathrm{t}$ & $\mathrm{t}$ & & $\mathrm{t}$ \\
isopropyl dihedral & & 82.3 & & -70.0 & & 162.4 \\
$\mathrm{NH}_{2}$ dihedral & & -168.9 & -165.9 & & -164.7 \\
population [\%] & & 0.1 & & 2.1 & & 1.8 \\
{$[\alpha]_{589}$} & & +14.0 & & +0.2 & & -6.2 \\
\hline
\end{tabular}

\section{Table 9B}

Calculated dihedrals and populations based on free energy differences weighted by the Boltzmann equation (mpw1pw91/cc-pvdz, IEFPCM: acetonitrile) and $[\alpha]_{589}$ values (mp1pw91/cc-pvdz, IEFPCM: acetonitrile) of the $\mathrm{NH}_{2}$ ax chair of (-)-(1S,3S,4S)-neoisomenthylamine

\begin{tabular}{lllllll}
\hline Isopropyl dihedral & $\mathrm{g}^{+}$ & $\mathrm{g}^{-}$ & $\mathrm{t}$ & $\mathrm{g}^{+}$ & $\mathrm{g}^{-}$ & $\mathrm{t}$ \\
$\mathrm{NH}_{2}$ dihedral & $\mathrm{g}^{+}$ & $\mathrm{g}^{+}$ & $\mathrm{g}^{+}$ & $\mathrm{g}^{-}$ & $\mathrm{g}^{-}$ & $\mathrm{g}^{-}$ \\
isopropyl dihedral & 51.2 & -83.6 & 179.6 & 49.0 & -82.9 & 175.5 \\
$\mathrm{NH}_{2}$ dihedral & 48.8 & 54.2 & 52.2 & -70.0 & -69.7 & -65.0 \\
population [\%] & 0.2 & 0.6 & 9.8 & 0.8 & 1.9 & 30.2 \\
{$[\alpha]_{589}$} & +47.83 & -26.91 & +18.44 & +63.49 & -22.48 & +23.19 \\
\hline Isopropyl dihedral & & $\mathrm{g}^{+}$ & & $\mathrm{g}^{-}$ & & $\mathrm{t}$ \\
$\mathrm{NH}_{2}$ dihedral & & $\mathrm{t}$ & & $\mathrm{t}$ & & $\mathrm{t}$ \\
isopropyl dihedral & & 50.9 & & -79.7 & & 174.9 \\
$\mathrm{NH}_{2}$ dihedral & & 174.3 & & -179.0 & & 175.0 \\
population [\%] & & 0.6 & & 1.0 & & 15.8 \\
{$[\alpha]_{589}$} & & +129.1 & & +63.76 & & +109.47 \\
\hline
\end{tabular}

\section{Table 10}

Calculated dihedrals and populations of four conformers (mpw1pw91/cc-pvdz, IEFPCM: acetonitrile) and $[\alpha]_{589}$ values (mp1pw91/cc-pvdz, IEFPCM: acetonitrile) of $(-)-(1 S, 3 S, 4 S)$-neoisomenthylamine.

\begin{tabular}{lllll}
\hline & $\mathrm{NH}_{2} \mathrm{eq}$ & $\mathrm{NH}_{2} \mathrm{eq}$ & $\mathrm{NH}_{2} \mathrm{ax}$ & $\mathrm{NH}_{2} \mathrm{ax}$ \\
\hline isopropyl dihedral & $\mathrm{t}$ & $\mathrm{t}$ & $\mathrm{t}$ & $\mathrm{t}$ \\
$\mathrm{NH}_{2}$ dihedral & $\mathrm{g}^{+}$ & $\mathrm{g}^{-}$ & $\mathrm{g}^{+}$ & $\mathrm{g}^{-}$ \\
isopropyl dihedral & -151.3 & -161.3 & 179.6 & 175.5 \\
$\mathrm{NH}_{2}$ dihedral & 67.4 & -56.6 & 52.2 & -65.0 \\
population [\%] & 12.8 & 27.9 & 14.5 & 44.8 \\
{$[\alpha]_{589}$} & -105.88 & -26.08 & +18.44 & +23.19 \\
{$[\alpha]_{578}$} & -110.38 & -27.10 & +19.13 & +24.08 \\
{$[\alpha]_{365}$} & -327.37 & -69.53 & +45.68 & +59.12 \\
\hline
\end{tabular}

\subsection{Linear regression of experimental and calculated optical rotation values}

Experimental and calculated ORD values of the (+)-menthol and (+)-menthylamine (base and $\mathrm{HCl} /$ protonated) isomers were collected and a linear regression performed (Fig. 2).

Data pairs at shorter wavelengths for the amino isomers (base and $\mathrm{HCl} /$ protonated) were excluded as incorrect calculations near excitation wavelengths can lead to substantial error. The menthol isomers do not suffer from this shortcoming due to lower excitation wavelengths of the alcohols compared to the amines.

In Fig. 2, the data pairs together with the regression line (in red) and the prediction bands (in green) at a 99\% level of confidence (Origin ${ }^{\mathrm{R}}$ ) [65] are shown (experimental values were inverted if only values for the (-)-enantiomer were available; all calculated values belong to the $(+)$-enantiomer). The regression parameters are as follows: slope (0.885; standard error: 0.063), intercept (7.0, standard error: 3.12$), \mathrm{R}^{2}=0.892$.

Experimental optical rotation values below 5 cannot be predicted reliably at a $99 \%$ level of confidence. This is nicely demonstrated on the left side of Fig. 2 (close-up of the right side of Fig. 2) where the lower confidence interval intersects the x-axis near an optical rotation value of 5 . On top of the range of unreliably

\section{Table 11}

Calculated optical rotational values of $(-)-(1 S, 3 S, 4 S)$-neoisomenthylamine base using the four conformers of Table 10 and experimental ORD values of $(+)-(1 R, 3 R, 4 R)$-neoisomenthylamine.

\begin{tabular}{lcr}
\hline Wavelength in $\mathrm{nm}$ & {$[\alpha]_{\exp }$} & {$[\alpha]_{\text {calc }}$} \\
\hline 589 & $+11.0^{\mathrm{a}}$ & -7.8 \\
578 & $+15.4^{\mathrm{b}}$ & -8.1 \\
365 & $+24.1^{\mathrm{b}}$ & -28.2 \\
\hline a $\mathrm{c}=$ between 2 and 4, $\mathrm{CHCl}_{3}[63]$. & & \\
$\mathrm{b} 20{ }^{\circ} \mathrm{C}[64]$. & &
\end{tabular}


Table 12

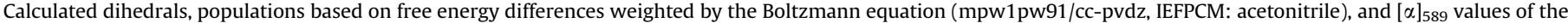
$\mathrm{NH}_{2}$ eq and $\mathrm{NH}_{2}$ ax chairs of protonated (-)-(1S,3S,4S)-neoisomenthylamine adjusted for comparison with the experimental values of the hydrochloride.

\begin{tabular}{|c|c|c|c|c|c|c|}
\hline & eq/eq/ax & eq/eq/ax & eq/eq/ax & $\mathrm{ax} / \mathrm{ax} / \mathrm{eq}$ & $\mathrm{ax} / \mathrm{ax} / \mathrm{eq}$ & $\mathrm{ax} / \mathrm{ax} / \mathrm{eq}$ \\
\hline isopropyl dihedral & $\mathrm{g}^{+}$ & $\mathrm{g}^{-}$ & $\mathrm{t}$ & $\mathrm{g}^{+}$ & $\mathrm{g}^{-}$ & $\mathrm{t}$ \\
\hline isopropyl dihedral & 80.9 & -73.3 & -151.3 & 51.1 & -83.6 & 179.6 \\
\hline population [\%] & 0.4 & 13.0 & 47.9 & 1.0 & 1.8 & 35.9 \\
\hline$[\alpha]_{589}$ & -17.8 & -54.5 & -39.6 & +84.7 & +4.9 & +44.0 \\
\hline$[\alpha]_{546}$ & -20.9 & -64.0 & -46.4 & +99.2 & +5.6 & +51.4 \\
\hline
\end{tabular}
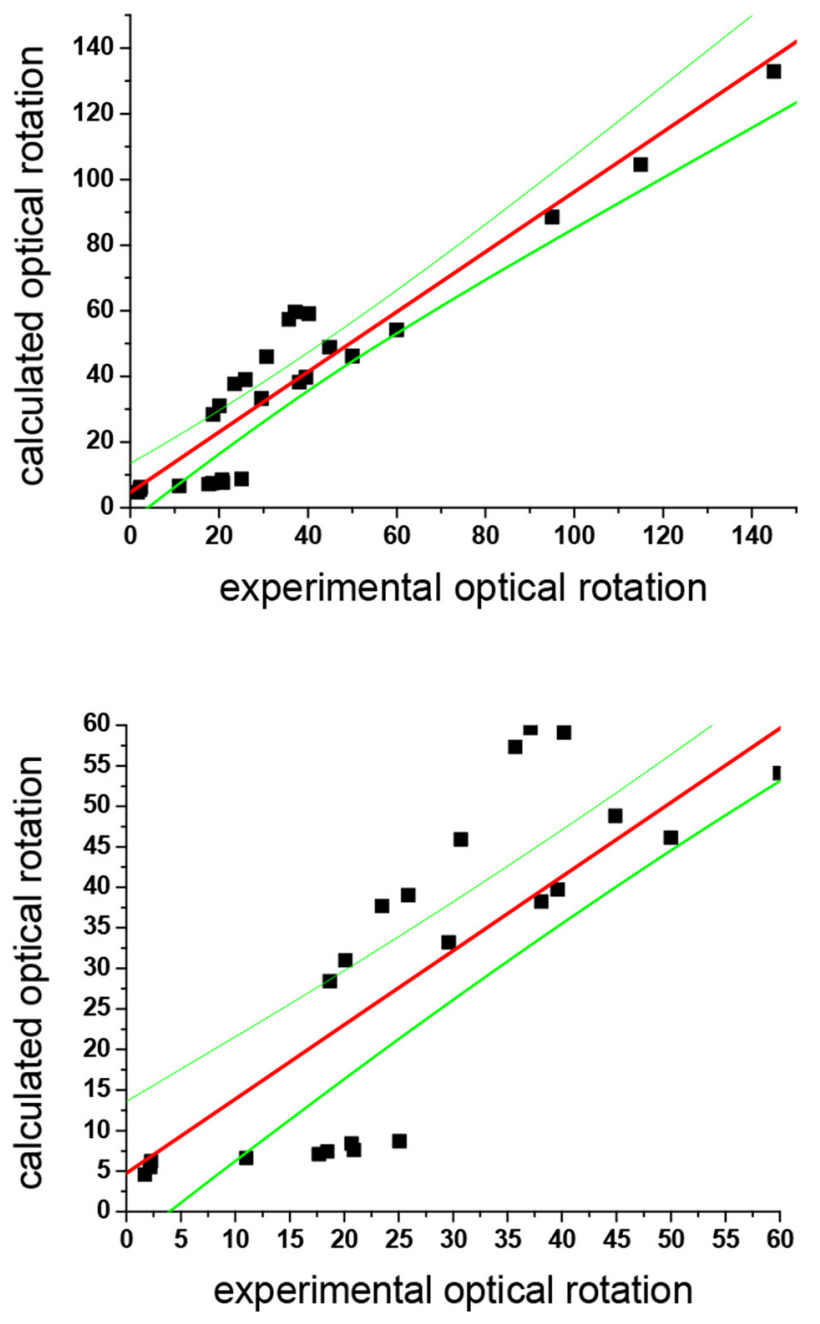

Fig. 2. Top: Experimental and calculated ORD values (in total: 26) of the (+)-menthol and $(+)$-menthylamine (base and $\mathrm{HCl}$ /protonated) isomers; linear regression lines (in red) and prediction bands at a 99\% level of confidence (in green, Origin ${ }^{\mathrm{TM}}$ ) [65]; bottom: close up in the region of small values; experimental values were inverted if only values for the (-)-enantiomer were available; all calculated values belong to the $(+)$-enantiomer, the list of data pairs can be found below the figure.

predictable ORD data we added the variation originating from the different levels of theory used. Based on our work on limonene [29], we assumed an additional range of uncertainty of 5 units. Adding these two contributions, we propose not to predict the absolute configuration of a compound if this prediction is solely based on the comparison of experimental and calculated ORD data with experimental values that are within the range of \pm 10 . This parallels the mean absolute error of 9.5 (sum of the absolute differences between experimental and calculated values, divided by the number of data pairs). Systematically underestimated are the calculated values for some neo and neoiso forms.
List of data pairs for Fig. 2 (taken from the tables of the main text and supporting information)

\begin{tabular}{llrr}
\hline Compound & Wavelength & {$[\alpha]$ exp. } & {$[\alpha]$ calc. } \\
\hline (+)-menthol & 589 & 50.0 & 46.1 \\
& 546 & 60.0 & 54.1 \\
& 436 & 95.0 & 88.5 \\
& 405 & 115.0 & 104.5 \\
(+)-neomenthol & 365 & 145.0 & 132.9 \\
& 589 & 17.7 & 7.1 \\
& 578 & 18.5 & 7.4 \\
(+)-isomenthol & 546 & 20.7 & 8.4 \\
& 656 & 20.1 & 31.0 \\
& 589 & 25.9 & 39.0 \\
(+)-neoisomenthol & 546 & 30.7 & 45.9 \\
& 486 & 40.2 & 59.1 \\
(+)-menthylamine & 656 & 1.7 & 4.6 \\
& 589 & 2.2 & 5.5 \\
(+)-neomenthylamine & 546 & 2.3 & 6.2 \\
(+)-isomenthylamine & 589 & 35.7 & 57.3 \\
(+)-neoisomenthylamine & 578 & 37.1 & 59.6 \\
(+)-menthylamine (protonated/HCl & 589 & 8.7 & 25.1 \\
& 589 & 29.6 & 33.2 \\
& 589 & 11.0 & 7.8 \\
(+)-neomenthylamine (protonated/HCl) & 589 & 38.1 & 38.1 \\
(+)-isomenthylamine (protonated/HCl) & 589 & 39.6 & 39.7 \\
(+)-neoisomenthylamine (protonated/HCl) & 589 & 44.9 & 48.8 \\
& 578 & 18.7 & 28.4 \\
& 546 & 23.5 & 37.7 \\
& 20.9 & 9.4 \\
\hline
\end{tabular}

\section{Discussion}

Kondru et al. [66] investigated the conformational dependence of optical rotation with menthol as one of the test molecules. Without presenting further information concerning population and geometry, two conformers were used and a value of 33.3 for the specific optical rotation predicted. This resembles our value when the three conformers lowest in energy were taken, together with Boltzmann-based populations. It might be argued that MD modelling together with high level ORD calculations should be used as gold standard. However, even this approach has clear shortcomings as illustrated by Kundrat and Autschbach [67] by use of extensive MD modelling for the prediction of specific optical rotation values. The experimental values for the two test molecules (proline and phenylalanine) in water $(-99.2$ and -57$)$ were most accurately predicted by an older study using static geometries and the COSMO solvent model (-101.5 and -36.8) [67]. In contrast, the MD simulation with COSMO as solvent model delivered values of -63.3 and -16.1 for proline and phenylalanine, respectively. One crucial point in MD modelling is the force field. Especially $\mathrm{H}$ bonding is a difficult property to predict [68]. In the very early study of Polavarapu and Chakraborty [69] the dependence of the optical rotation of chiral 3-butyn-2-ol for different conformers was investigated. The optical rotation was highly dependent on the $\mathrm{OH}$ rotamer $(-80.8,-30.0$, and +69.7 for the three staggered 
conformers).

Galisteo et al. [62] investigated the empirical relationship between structure and optical rotation of the menthol and menthylamine (as bases) stereoisomers. A forcefield (MM2) was used for the conformational search and the population analysis, whereas a purely empirical approach was used to assign contributions of molecular fragments to the overall optical rotation. For all 8 enantiomeric menthol isomers the optical rotation sign was successfully predicted. A follow-up study [70] indicated that other calculation schemes (MM3, semiempirical AM1) predicted the incorrect sign for neoisomenthol.

Menthol has also been used as model compound for the development of chiroptical methods such as VCD and Raman optical activity (ROA) [71]. The conformational flexibility of the other isomers leads to complex data that are much more difficult to interpret. A recent study selected (-)-menthol to analyse the hydrogen bonding network using IR, Raman, and VCD as experimental techniques, together with DFT calculations [34]. Even for menthol, the most rigid isomer within the series, different levels of theory delivered different orderings of energies, which subsequently leads to different population mixes. Depending on the level of theory, two conformers were at lowest energy: the $g^{-} /$trans and $g^{-} / g^{-}$(isopropyl/OH dihedral). With the B3LYP/cc-pVDZ level of theory the second conformer was $0.3 \mathrm{kcal} / \mathrm{mol}$ higher in energy, whereas on the B3LYP/6-31 + $\mathrm{G}^{*}$ level of theory the first conformer was $0.2 \mathrm{kcal} / \mathrm{mol}$ higher in energy. In the group of five conformers with lowest energy, the maximum deviation between the two levels of theory was $1.0 \mathrm{kcal} / \mathrm{mol}$. Such large differences might affect the calculated spectra. Even with the use of a set of scaling factors, a comparison between experimental and calculated IR and VCD spectra showed large discrepancies. This is not surprising if errors in calculating anharmonic effects are taken into account [72].

Neoisomenthol presents a special configurational problem due to its very low specific optical rotation, lack of ECD bands in the UV/ Vis region, and a high conformational flexibility. Even at shorter wavelengths the ORD values do not increase much, however, indicate a monosignate curve like all other menthol isomers [40]. Likewise, neoisomenthylamine as base appears to be sensitive towards temperature and impurities. It is therefore a difficult task to reliably assign the sign of the optical rotation which is conventionally taken from ethanol solution to the $R / S$ nomenclature. Therefore, we present a line of arguments proofing that the original assignment $(1 R, 3 R, 4 R)$ for $(+)$, and $(1 S, 3 S, 4 S)$ for $(-)$ is correct. It is important to note that the four menthol diastereomers can be separated by various methods, one being gas chromatography [73].

Paine III [40] synthesized neoisomenthol from isomenthone with a known absolute configuration $(1 R, 4 R)$, so that the $(1 R, 3 R, 4 R)$ form of neoisomenthol was obtained. Then, a di-terephtalate derivative was prepared, and following ester cleavage, $(1 R, 3 R, 4 R)$ neoisomenthol was formed (purity of $99.3 \%$ by gas chromatography). The optical rotation of the neat compound at $20.0{ }^{\circ} \mathrm{C}$ (variation of less than $0.2{ }^{\circ} \mathrm{C}$ ) with $10 \mathrm{~cm}$ path length was $+0.406,+0.425$, and +0.473 for $589 \mathrm{~nm}, 578 \mathrm{~nm}$, and $546 \mathrm{~nm}$ respectively. A synthetic route via the 2,6-naphtalenedicarboxylate gave values of $+0.137,+0.140$, and +0.148 . From this we can assign a $(+)$ sign of the $[\alpha]_{589}$ value for the neat compound with the $(1 R, 3 R, 4 R)$ form. Since Read and Grubb [46] (Table S21 in the supporting information) presented data of a $(+)[\alpha]_{589}$ value for the neat compound which also showed $a(+)$ sign when measured in ethanol, we can assign the same sign of the neat compound to the solution in ethanol.

Next, it was important to derive the isomenthone configuration. It was synthesized from $(+)-(1 R, 3 S, 4 R)$ isomenthol. The proof that this is the correct assignment can be taken from the publication of Kartha et al. [14]. They determined by the heavy atom method and anomalous x-ray dispersion, the absolute configuration of the isomenthyl derivative together with the chiroptical information Putting the pieces together, from assigned isomenthol, and via isomenthone, a neoisomenthyl derivative was synthesized which corresponds to the $(1 R, 3 R, 4 R)$ form. This form, following ester cleavage, resulted in neoisomenthol with a $(+)[\alpha]_{589}$ value in ethanol. The correct assignment is therefore $(+)-(1 R, 3 R, 4 R)-$ neoisomenthol using ethanol as solvent, as can be found in the literature.

Taking into account the difficulties in the AC assignment of neoisomenthol, it is not surprising that some configurational information in the literature of the amino derivative must be revised. Bose et al. [74] claimed to have assigned the AC of isomenthol and neoisomenthylamine. However, both assignments are incorrect. Similarly, Kozlov et al. [75] assigned the AC of isomenthylamine incorrectly. In their report, the optical rotation was measured in ethanol as solvent which might explain the error since other optical rotation data with this solvent are not available for isomenthylamine and neoisomenthylamine. For the latter compound, it is still possible that Kozlov et al. [75] by chance assigned the AC correctly. The correct assignment was presented by Read and Robertson [61]. Starting from $d-(+)$-isomenthone, the dextrorotatory (in chloroform as solvent) neoisomenthylamine base was prepared. Experimental data for the pure compound were presented in 1930 by Read and Storey [76]. In contrast to $(1 R, 3 R, 4 R)$-neoisomenthol, a sign change did not occur, thus $(1 R, 3 R, 4 R)$-neoisomenthylamine base remains dextrorotatory when measured as a homogenous sample.

\section{Conclusion}

We have shown that the AC of all 12 compounds, even in the case of the most difficult neoiso forms, can be predicted correctly using experimental NMR data. If only experimental data with an optical rotation outside the range of $-10<[\alpha]>10$ are used, all 12 compounds were correctly assigned even without low-temperature NMR data as restraints for the conformational analysis.

\section{Computational section}

Models of the menthol and menthylamine (base and protonated) isomers were built in GaussView 5.0. A conformational search using the BEST algorithm with the CHARMm force field and a cutoff of $2 \mathrm{kcal} / \mathrm{mol}$ was performed using DISCOVERY Studio (Accelrys, 2009) [20]. DFT calculations were performed with Gaussian09 [21] (RevA.02, Frisch et al., 2009) on the mpw1pw91/cc-pvdz (IEFPCM: acetonitrile as solvent) level of theory (unless other solvents are indicated) for geometry optimization, energy calculations, and spectroscopic properties. For the calculation of the specific optical rotation of neoisomenthol, two additional levels of theory were used as indicated: mpw1pw91/aug-cc-pvdz and mpw1pw91/ cc-pvtz. Energies were obtained at $298.15 \mathrm{~K}$ and $1 \mathrm{~atm}$ of pressure. The lowest energy conformer was taken as reference, set to $0 \mathrm{kcal} /$ mol (conversions used: 1 Hartree $=627.5 \mathrm{kcal} ; 1 \mathrm{cal}=4.18 \mathrm{~J}$ ) and the resulting energy differences were used to calculate populations according to the Boltzmann distribution. In all calculations the Polarizable Continuum Model (PCM) using the integral equation formalism variant (IEFPCM) implemented in G09 was used as solvent model. The unit of $[\alpha]$ is $\left[\right.$ degrees $\left.^{*}\left(\mathrm{dm}^{*} \mathrm{~g} / \mathrm{cm}^{3}\right)^{-1}\right]$. Experimental ORD values from literature are listed in the supporting information.

\section{Acknowledgements}

We want to thank the DFG (FOR 934) and the MPG (MPIBPC: 
Department for NMR-based structural biology, Prof. Griesinger) for support. We gratefully acknowledge the careful reading of the manuscript by Dr. T. Schweizer.

\section{Appendix A. Supplementary data}

Supplementary data related to this article can be found at http:// dx.doi.org/10.1016/j.molstruc.2015.09.013.

\section{References}

[1] J.R. Hanson, Nat. Prod. Rep. 18 (2001) 607-617.

[2] R.B. Croteau, E.M. Davis, K.L. Ringer, M.R. Wildung, Naturwissenschaften 92 (2005) 562-577.

[3] J. Kulisch, M. Nieger, F. Stecker, A. Fischer, S.R. Waldvogel, Angew. Chem. Int. Ed. 24 (2011) 5564-5567.

[4] J.H. Gladstone, J. Chem. Soc. 17 (1864) 1-21.

[5] B. Schäfer, Chem. Unserer Zeit 47 (2013) 174-182.

[6] M. B. Erman, P. J. Whelan, US patent 2007, 7,189,760 B2.

[7] P. Bombicz, J. Buschmann, P. Luger, N. Xuan Dung, C. Ba Nam, Z. Krist. 214 (1999) 420-423.

[8] E.E. Kwan, S.G. Huang, Eur. J. Org. Chem. (2008) 2671-2688.

[9] H.D. Orloff, Chem. Rev. 54 (1954) 347-447.

[10] M. Marianski, A. Asensio, J.J. Dannenberg, J. Chem. Phys. (2012), 137, 044109.

[11] E.A. Basso, C.A. Abiko, G.F. Gauze, R.M. Pontes, J. Org. Chem. 76 (2011) 145-153.

[12] J. Shen, Y. Li, R. Vaz, H. Izumi, J. Chem. Theory Comput. 8 (2012) 2762-2768.

[13] B. Mennucci, C. Cappelli, R. Cammi, J. Tomasi, Chirality 23 (2011) 717-729.

[14] G. Kartha, K.T. Go, A.K. Bose, M.S. Tibbetts, J. Chem. Soc. Perkin II (1976) $717-723$.

[15] J. Härtner, U.M. Reinscheid, J. Mol. Struct. 872 (2008) 145-149.

[16] T.I. Pehk, E.T. Lippmaa, V.I. Lysenko, I.I. Bardyshev, Russ. J. Org. Chem. (1980) 1694-1703.

[17] D.A. Lanfranchi, M.-C. Blanc, M. Vellutini, P. Bradesi, J. Casanova, F. Tomi, Magn. Reson. Chem. 46 (2008) 1188-1194.

[18] W. Hückel, H. Niggemeyer, Ber. Dtsch. Chem. Ges. 72 (1939) 1354-1358.

[19] J. Catalán, J. Phys. Chem. B 113 (2009) 5951-5960.

[20] Accelrys, Discovery Studio, 2009.

[21] M.J. Frisch, et al., GaussianG09, Revision A.02, Gaussian, Inc., Wallingford CT, 2009.

[22] F. Gangemi, R. Gangemi, G. Longhi, S. Abbate, Phys. Chem. Chem. Phys. 11 (2009) 2683-2689.

[23] S. Qiu, E. De Gussem, K.A. Therani, S. Sergeyev, P. Bultinck, W. Herrebout, J. Med. Chem. 56 (2013) 8903-8914.

[24] L. Rottmannová, V. Lukeš, M. IlčP Fodran, P. Herich, J. Kožišek, T. Liptaj, E. Klein, J. Mol. Struct. 1049 (2013) 494-501.

[25] J. Fohrer, U. Reinscheid, M. Hennig, T. Carlomagno, Angew. Chem. Int. Ed. 45 (2006) 7033-7036.

[26] S. Nozinovic, P. Gupta, B. Fürtig, C. Richter, S. Tüllmann, E. Duchardt-Ferner, M.C. Holthausen, H. Schwalbe, Angew. Chem. Int. Ed. 50 (2011) 5397-5400.

[27] C. Benzi, O. Crescenzi, M. Pavone, V. Barone, Magn. Reson. Chem. 42 (2004) S57-S67.

[28] P.L. Polavarapu, Chirality 24 (2012) 909-920.

[29] F. Reinscheid, U. M. Reinscheid, J. Mol. Struct., (submitted).

[30] M. Schmidt, F. Reinscheid, H. Sun, H. Abromeit, G.K.E. Scriba, F.D. Sönnichsen, M. John, U.M. Reinscheid, Eur. J. Org. Chem. (2014) 1147-1150.

[31] F. Reinscheid, M. Schmidt, H. Abromeit, S. Liening, G. K. E. Scriba, U. M. Reinscheid, J. Mol. Struct. , (submitted) for publication.

[32] J.S. Lomas, Magn. Reson. Chem. 52 (2014) 745-754.

[33] M. Albrecht, J. Will, M.A. Suhm, Angew. Chem. Int. Ed. 49 (2010) 6203-6206.

[34] J.R. Avilés Moreno, F. Partal Urena, J.J. Lopez González, Struct. Chem. 24 (2013)
671-680.

[35] T. Egawa, M. Sakamoto, H. Takeuchi, S. Konaka, J. Phys. Chem. A 107 (2003) 2757-2762.

[36] J. L. McCann, 1998, Dissertation, Department of Chemistry, University of Calgary, Alberta, Canada.

[37] D. Schmitz, V.A. Shubert, T. Betz, M. Schnell, Front. Chem. 3 (2015) 15.

[38] Y. Senda, S. Imaizumi, Tetrahedron 31 (1975) 2905-2908.

[39] R.B. Jensen, Act. Chem. Scand. 22 (1968) 1271-1278.

[40] J.B. Paine III, Philipp Morris USA Confidential, 1997 research center, Doc code P0622;

[40a] JASCO application note, www.jascoinc.com/docs/application-notes/p0002_e.pdf?sfvrsn $=$.

[41] P.L. Polavarapu, Chirality 18 (2006) 348-356.

[42] Y.M. Grigorèv, S.M. Morozov, O.V. Sverdlova, J. Appl. Spectrosc. 23 (1975) 1362-1364.

[43] W. Hückel, H. Feltkamp, S. Geiger, Liebigs Ann. Chem. 637 (1960) 1-19.

[44] D. Voisin, B. Gastambide, Bull. Soc. Chim. 7 (1971) 2643-2651.

[45] J.B. Hendrickson, J. Am. Chem. Soc. 86 (1964) 4854-4866.

[46] J. Read, W.J. Grubb, J. Chem. Soc. (1934) 313-317.

[47] W. Hückel, S. Gupte, Chimia 20 (1966) 276.

[48] A.R.H. Cole, P.R. Jefferies, J. Chem. Soc. (1956) 4391-4397.

[49] R.J. Abraham, E.J. Chambers, W.A. Thomas, J. Chem. Soc. Perkin Trans. 2 (1993) 1061-1066.

[50] R.J. Abraham, T.A.D. Smith, W.A. Thomas, J. Chem. Soc. Perkin Trans. 2 (1996) 1949-1955.

[51] T. Tominaga, S. Tenma, H. Watanabe, J. Chem. Soc. Faraday Trans. 92 (1996) 1863-1867.

[52] H. Feltkamp, N.C. Franklin, Tetrahedron 21 (1965) 1541-1546.

[53] P.R. de Oliveira, L. Tasic, S.A. Rocco, R. Rittner, Magn. Reson. Chem. 44 (2006) $790-796$.

[54] G. Gill, D.M. Pawar, E.A. Noe, J. Org. Chem. 70 (2005) 10726-10731.

[55] J. Firl, G. Kresze, T. Bosch, V. Arndt, Liebigs Ann. Chem. (1978) 87-97.

[56] M.C. Schopohl, K. Bergander, O. Kataeva, R. Fröhlich, S.R. Waldvogel, Synthesis 17 (2003) 2689-2694.

[57] D.A. de Vekki, V.M. Uvarov, A.N. Reznikov, N.K. Skvortsov, Russ. Chem. Bull. Int. Ed. 57 (2008) 349-357.

[58] Y. Zhou, J. Dong, F. Zhang, Y. Gong, J. Org. Chem. 76 (2011) 588-600.

[59] Y. Zhou, Y. Gong, Eur. J. Org. Chem. (2011) 6092-6099. Y. Zhou, Q. Liu, Y. Gong, Org. Biomol. Chem. 2012, 10, 7618-7627; H. Yuan, J. Hu, Y. Gong, Tetrahedron: Asymmetry 2013, 24, 699-705; Y. Zhou, Y. Zhu, S. Yan, Y. Gong Angew. Chem. Int. Ed. 2013, 52, 10265-10269; Y. Zhou, Q. Liu, Y. Gong, Tetrahedron Lett. 2013, 54, 3011-3014.

[60] P. Jumaryatno, K. Rands-Trevor, J.T. Blanchfield, M.J. Garson, Arkivoc (2007) $157-166$.

[61] J. Read, G.J. Robertson, J. Chem. Soc. (1927) 2168-2174.

[62] D. Galisteo, M.E. González-Vadillo, J.A. López Sastre, M.H. Martinez Garcia, J.F. Rodriguez Amo, J. Mol. Struct. 326 (1994) 239-247.

[63] J. Read, W.W. Cuthbertson, Rec. Chim. Pays-Bas 69 (1950) 539-544.

[64] H. Feltkamp, F. Koch, T.N. Thanh, Liebigs Ann. Chem. 707 (1967) 78-86.

[65] Origin TM, Version 6, Microsoft, 1999.

[66] R.K. Kondru, P. Wipf, D.N. Beratan, J. Phys. Chem. A 103 (1999) 6603-6611.

[67] M.D. Kundrat, J. Autschbach, J. Am. Chem. Soc. 130 (2008) 4404-4414.

[68] J.-H. Lii, N.L. Allinger, J. Phys. Chem. A 112 (2008) 11903-11913.

[69] P.L. Polavarapu, D.K. Chakraborty, Chem. Phys. 240 (1999) 1-8.

[70] R. Núnez Miguel, J.A. Lopez Sastre, D. Galisteo, A. Diez Martin, A. Gordaliza Ramos, J. Mol. Struct. 522 (2000) 219-231.

[71] L.D. Barron, L. Hecht, S.M. Blyth, Spectrochim. Acta 45A (1989) 375-379.

[72] M. Biczysko, P. Panek, G. Scalmani, J. Bloino, V. Barone, J. Chem. Theory Comput. 6 (2010) 2115-2125.

[73] D.R. Moore, A.D. Kossoy, J. Chem. Ed. 33 (1961) 1437.

[74] A.K. Bose, S. Harrison, L. Farber, J. Org. Chem. 28 (1963) 1223-1225.

[75] N.G. Kozlov, T.I. Pekh, T.K. Vyalimyaé, Chem. Nat. Compd. 17 (1982) 238-243.

[76] J. Read, R.A. Storey, J. Chem. Soc. (1930) 2761-2769. 